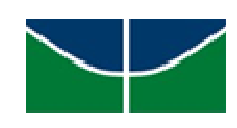

UNIVERSIDADE DE BRASÍLIA

FACULDADE DE ECONOMIA, ADMINISTRAÇÃO E CONTABILIDADE PROGRAMA DE PÓS-GRADUAÇÃO EM ADMINISTRAÇÃO

LEONEL CERQUEIRA SANTOS

\title{
MUITO ALÉM DA TECNOLOGIA: O IMPACTO DOS MECANISMOS NÃO OPERACIONAIS NA EFETIVIDADE DA GOVERNANÇA DE TI NA ADMINISTRAÇÃO PÚBLICA
}




\section{MUITO ALÉM DA TECNOLOGIA: O IMPACTO DOS MECANISMOS NÃO OPERACIONAIS NA EFETIVIDADE DA GOVERNANÇA DE TI NA ADMINISTRAÇÃO PÚBLICA}

Dissertação de Mestrado apresentada ao Programa de Pós-Graduação em Administração, da Universidade de Brasília.

Área de concentração: Estratégia, Marketing e Inovação.

ORIENTADOR: Carlos Denner dos Santos Júnior 


\section{AGRADECIMENTOS}

À Deus por mais uma vitória.

Aos meus pais pelo apoio.

Ao professor Carlos Denner dos Santos Júnior pela sua dedicação, disponibilidade, paciência e profissionalismo durante este período de convivência. 


\section{RESUMO}

A administração pública brasileira pode definir e construir as suas ações institucionais pautadas no papel dos stakeholders e na implantação da Nova Gestão Pública/Nova Governança Pública. Estas influências se refletem na tecnologia da informação governamental e na efetividade da sua governança a qual está em consonância com a governança corporativa e com o papel estratégico da TI, logo exigindo a adoção de mecanismos que transpõe aspectos operacionais. Desta forma, esta dissertação propõe uma análise dos mecanismos não operacionais que podem impactar na efetividade da governança da tecnologia da informação na administração pública. Neste estudo utilizou-se um questionário, aplicando-o em representantes da área de TI de organizações da administração pública. A partir dos dados coletados, ocorreu a aplicação do método estatístico denominado equações estruturais, verificando o impacto dos seguintes mecanismos na efetividade da governança de TI: Suporte da alta administração; Atuação do comitê de direção de TI; Atuação da gestão de portfólio de investimentos de TI; Utilização do planejamento estratégico de TI.O estudo indica que o suporte da alta administração, a utilização do planejamento estratégico de TI e a atuação direta do comitê de TI não tem influência sobre a efetividade da governança de tecnologia da informação do setor público. Porém, a atuação da gestão de portfólio de investimentos de TI influencia direta e positivamente a efetividade, inclusive através da sua presença como variável mediadora é que a atuação do comitê de TI tem efeito significativo sobre a efetividade da governança de TI pública. Com os resultados obtidos, este trabalho almeja contribuir para a literatura de governança de TI no contexto de que existem poucas pesquisas que examinam quais mecanismos contribuem para estabelecer essa efetividade dentro das organizações públicas, sendo este número ainda mais incipiente quando o ambiente se restringe ao setor público brasileiro. Assim, ao investigar o setor público nacional, este estudo deseja suprir parcialmente a carência de informações sobre a governança de TI aplicada a essa área.

Palavras-chaves: Efetividade. Governança de TI. Mecanismos de Governança de TI. Nova Gestão Pública. Nova Governança Pública. Stakeholders. Administração Pública Federal. 


\begin{abstract}
The Brazilian Public Administration can define and build their institutional actions based on the role of stakeholders and on implementation of New Public Management / New Public Governance. These influences reflects on the government information technology and on the effectiveness of its governance, which is in line with the corporate governance and the strategic role of IT, thus requiring the adoption of mechanisms that overpasses operational aspects. Therefore, this research proposes an analysis of non-operating mechanisms that can affect the effectiveness of the governance of information technology in public administration. This study used a questionnaire, applying it on representatives of IT organizations in the public administration field. At the data collected, a statistical method called structural equation was applied, verifying the impact of the following mechanisms on the effectiveness of IT governance: Senior management support; Performance of the IT director board committee; Portfolio management performance of investments on IT; Use of strategic planning on IT. The study indicates that the support of senior management, the use of IT strategic planning and the IT director board committee direct involvement has no influence on the effectiveness of information technology governance in the public sector. However, the performance of the IT investment portfolio management directly and positively influences the effectiveness, including through its presence as a mediator variable is that the performance of the IT committee has significant effect on the effectiveness of public IT governance. With the results obtained, this work aims to contribute to IT governance literature in the context that there are few studies that examine what mechanisms contribute to achieving such effectiveness within the public organizations, being this number is even more incipient when talking about the Brazilian public sector. Thus, by investigating the national public sector, this study wants to meet in part the lack of information on IT governance applied to this area.
\end{abstract}

Keywords: Effectiveness. IT governance. Mechanisms of IT Governance. New Public Management. New Public Governance. Stakeholders. Federal Public Administration. 


\section{SUMÁRIO}

1. Introdução

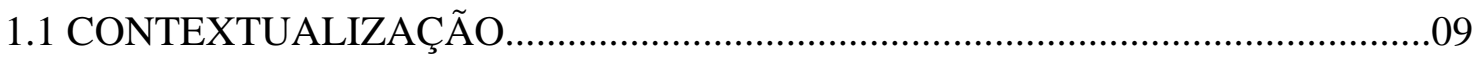

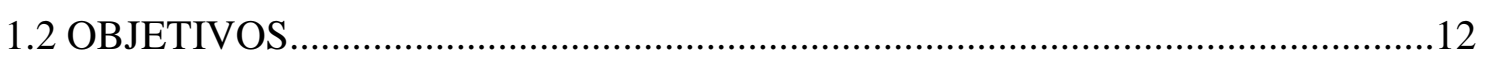

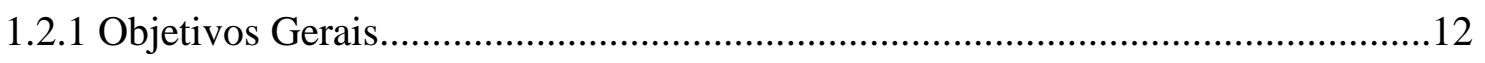

1.2.2 Objetivos Específicos....................................................................................12

Capítulo 2 - Referencial Teórico.................................................................14

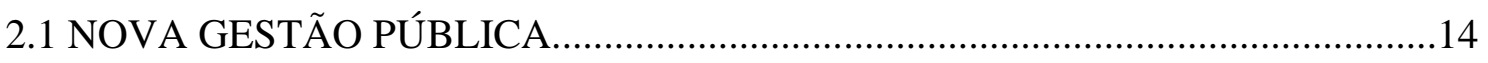

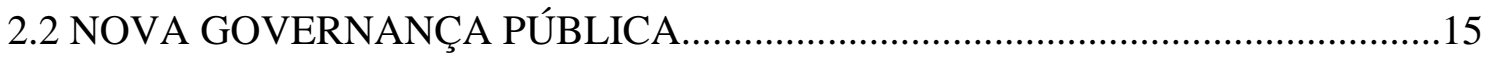

2.3 A GOVERNANÇA DE TI NA ADMINISTRAÇÃO PÚBLICA................................17

2.4 EFETIVIDADE DA GOVERNANÇA DE TI....................................................20

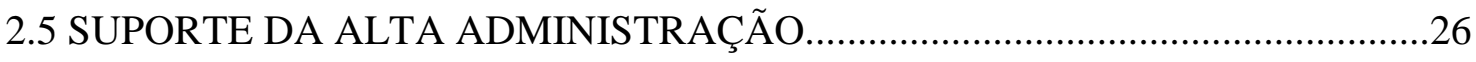

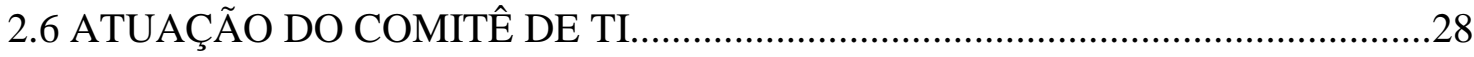

2.7 ATUAÇÃO DA GESTÃO DE PORTFOLIO DE INVESTIMENTOS DE TI.........30

2.8 UTILIZAÇÃO DO PLANEJAMENTO ESTRATÉGICO DE TI...............................31

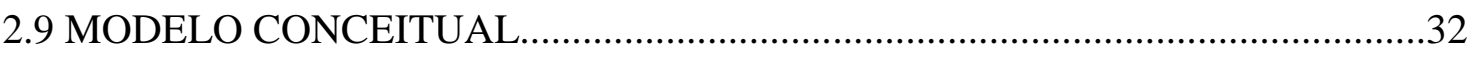

Capítulo 3 - Metodologia da Pesquisa............................................................

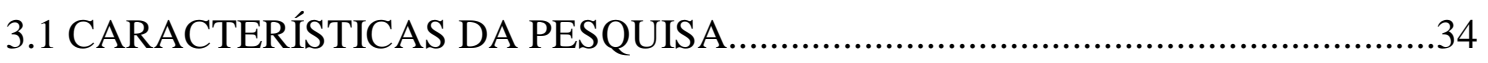

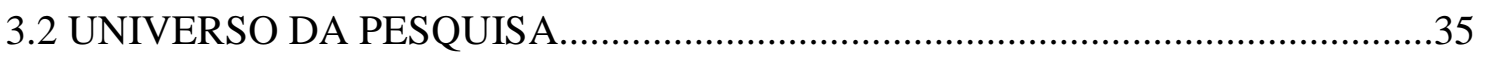

3.3 PROCEDIMENTOS DE COLETA, TRATAMENTO E ANÁLISE DE DADOS..36

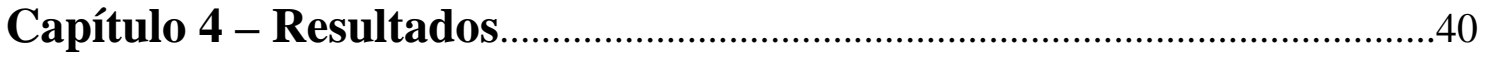

4.1 CARACTERÍSTICAS DA AMOSTRA E DO MODELO_........................................40

4.2 RESULTADO DO TESTE DE HIPÓTESES..........................................................4

Capítulo 5 - Discussão e Considerações Finais................................................52

5.1 ANÁLISE E INTERPRETAÇÃO DOS RESULTADOS DA PESQUISA................52

5.2 LIMITAÇÕES DA PESQUISA E SUGESTÕES DE TRABALHOS FUTUROS..57

Referências Bibliográficas..............................................................................5

Anexos 


\section{LISTA DE FIGURAS}

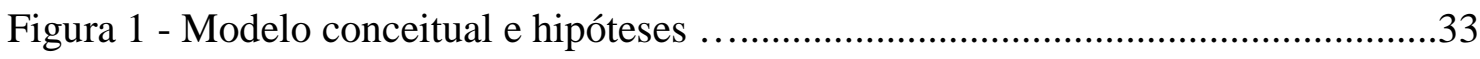

Figura 2 - Modelo estrutural/medida e hipóteses..........................................................39

Figura 3 - Gráfico sobre os tipos de organização que participaram da pesquisa..............41

Figura 4 - Gráfico sobre o tempo de serviço dos respondentes dentro da instituição.....42

Figura 5 - Modelo estrutural com os valores estimados e significâncias das hipóteses..51 


\section{LISTA DE TABELAS}

Tabela 1 - Resultados do teste qui-quadrado de ajustamento........................................45

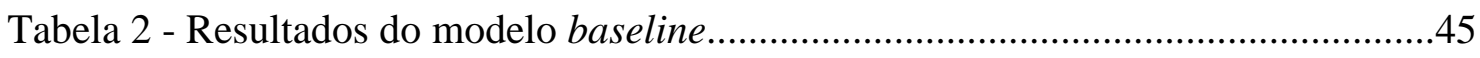

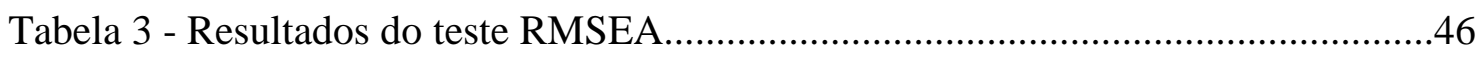

Tabela 4 - Resultados da relação entre as variáveis do modelo......................................48

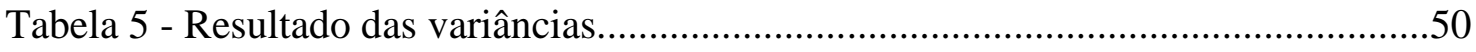




\section{INTRODUÇÃO}

\subsection{CONTEXTUALIZAÇÃO}

A administração pública brasileira tem o desafio de se ajustar a um mundo em constante mudança, no qual cresce a exigência da eficiência estatal aliada a um fornecimento de serviços públicos que possuam maior qualidade e que sejam calcados no controle social e na garantia dos direitos individuais (Bresser-Pereira, 2007; Imasato, Martins e Pieranti, 2011). Este desafio se caracteriza por ser um dos objetivos centrais do modelo teórico denominado Nova Gestão Pública o qual defende que o setor público deve ser administrado sob os preceitos de que os impactos das políticas governamentais devem demonstrar, além de eficiência, maior eficácia (Secchi, 2009).

Neste cenário, além da implementação do modelo gerencialista, as instituições públicas também se submetem à influência dos stakeholders para estabelecerem as suas atividades institucionais, pois as partes interessadas afetam a realização dos objetivos das organizações e são afetados pela realização dos objetivos da organização (Freeman e Reed, 1983).

Toda esta conjuntura influenciadora do setor público o conduz para a necessidade de solidificar a governança corporativa, pois esta auxilia as organizações na condução das suas decisões de tal forma a aprimorar o funcionamento governamental.

Esta ideia se torna mais forte quando o tema abordado é a tecnologia da informação, pois esta se constituiu como parte integrante da estratégia organizacional. A TI facilita a exploração e o uso de informações geradoras o que proporciona a ampliação dos benefícios, o aproveitamento das oportunidades e a promoção do crescimento organizacional (Mclean e Soden, 1977; Nolan, 1982; Brancheau e Wetherbe, 1987; Dixon e John, 1989; Raghunathan e Raghunathan, 1990; Niederman, Brancheau e Wetherbe, 1991; Davenport, 1993; Earl, 1993). 
Logo, dentro da área tecnológica se estabelece a governança de TI que é parte integrante da governança corporativa.

A governança de TI pode ser conceituada como um conjunto de mecanismos de estruturas, de processos e de relacionamentos que são definidos pela alta direção com vista a direcionar as ações de TI e exercer controle sobre o uso e a gestão desta.

Por conseguinte, a governança de TI objetiva estabelecer o melhor alinhamento entre o negócio e a tecnologia da informação da instituição para que sejam alcançados os objetivos organizacionais (Peterson, 2003; Weill e Ross, 2006; ISACA, 2011).

Estudos demonstram que uma governança de TI eficaz contribuiu para atenuar fraudes internas, identificando vários riscos de negócio e legais em áreas-chave de controle, tais como, as áreas de backup e sistemas de gerenciamento de dados, além de conseguir evitar fraudes que em outras ocasiões foram às bases para notáveis colapsos corporativos como a alteração indiscriminada de dados para ocultar problemas financeiros das organizações (IFAC, 2002; Weill e Ross, 2006; KPMG, 2010; Kranacher, Riley e Wells, 2010, Dechow et al., 2011; Lunardi, Becker e Maçada, 2012).

Assim, conforme relatado na definição de governança e nos exemplos acima, observase que a governança de TI é um constructo composto e orientado por princípios e operacionalizado por meio de mecanismos que são um conjunto de práticas e arranjos utilizados para operacionalizar os objetivos da governança de TI, os quais podem garantir a sua efetividade (Goodhue e Thompson, 1995; Macdonald, 2005; Bowen et al., 2007; Bernard, 2012).

Vários pesquisadores têm realizado estudos sobre as implementações dos mecanismos de governança de TI e o seu impacto na efetividade da governança, porém a maioria destes estudos tem por objeto o setor privado (Peterson, 2001; ITGI, 2003; Vaswani, 2003; Weill e 
Ross, 2004; Ali e Green, 2007; Bowen, Cheung e Rohde, 2007; Van Grembergen e De Haes, 2009; Huang, Zmud e Price, 2010; Liang et al, 2011; Heindrickson e Santos Jr., 2014).

Diante deste cenário, esta pesquisa objetiva identificar e examinar empiricamente um conjunto de mecanismos que impactam a efetividade de governança de TI dentro de organizações do setor público, pois esta difere do setor privado. Estas diferenças passam pelo fato de que o setor público sofre mais a influência do ambiente político, além de que sua sobrevivência depende mais do cumprimento de cerimoniais, ritos legais e mitos culturais do que a busca pela remuneração do capital investido e de resultados financeiros (Geraldo Loureiro e Souza Neto, 2012).

Este trabalho foca sua análise na observação de mecanismos de governança não operacionais. Estes mecanismos são definidos como um conjunto de arranjos e práticas que estão relacionados a aspectos estratégicos e táticos da governança tecnológica.

O estudo deste tipo de mecanismo é importante porque ele se coaduna com a ideia de que a governança de TI é de responsabilidade da alta administração (Weill e Ross, 2006; ABNT, 2009; BRASIL, 2010; ISACA, 2011). Além disso, mira-se estudar mecanismos influenciadores, ou seja, mecanismos que não somente atuam para efetividade, mais também norteiam a realização de outras atividades que contribuirão para a melhoria da governança de TI.

Assim, além de acrescentar mais um estudo dentro de um campo onde existem poucas $^{1}$ pesquisas que examinam quais fatores contribuem para estabelecer a efetividade de governança de TI dentro das organizações públicas, o objetivo deste estudo é de investigar, de

\footnotetext{
${ }^{1}$ Realizou-se uma revisão de literatura nas bases de dados da Capes, Proquest e BDTD e foram encontrados cinco trabalhos que trataram da relação entre mecanismos e efetividade da governança tecnológica em instituições públicas. Foram utilizadas as palavras-chave "Mecanismos de governança de TI" e "IT Governance Mechanisms", para depois analisar os resultados a fim de detectar pesquisas voltadas também para a efetividade da governança de TI na administração pública. A revisão foi realizada nos dias 8 e 9 de dezembro de 2014.
} 
forma empírica, as relações existentes entre os mecanismos não operacionais de governança de TI relatados anteriormente, no âmbito das instituições públicas federais.

Desta forma, o trabalho se diferencia dos outros estudos voltados para a área pública, pois estes se detiveram em escolher um amplo e diverso espectro de mecanismos, não focando apenas em componentes estratégicos e táticos (Ali e Green, 2007; Grant, 2007; Nfuka e Rusu, 2011; Winkler, 2013).

Cabe destacar que o conceito de efetividade abordado neste trabalho será relacionado a ideia da capacidade que uma instituição tem de corresponder às expectativas dinâmicas e mutantes em relação aos produtos, serviços e resultados gerados no seu próprio contexto (Cavalieri, Macedo-Soares e Thiollent, 2004).

Dessa forma, diante do contexto relatado, apresenta-se a seguinte questão: Quais mecanismos não operacionais impactam no nível de efetividade percebida da governança de tecnologia da informação da Administração Pública?

\subsection{OBJETIVOS}

\subsubsection{Objetivos Gerais}

Identificar as relações dos mecanismos de governança de TI não operacionais com a efetividade percebida da governança de TI em instituições públicas federais brasileiras.

\subsubsection{Objetivos Específicos}

i. Identificar se o suporte da alta administração têm influência direta e positiva na efetividade da governança de TI;

ii. Identificar se a atuação do comitê de TI têm influência direta e positiva na efetividade da governança de TI; 
iii. Identificar se a atuação da gestão de portfólio de investimento de TI têm influência direta e positiva na efetividade da governança de TI;

iv. Identificar se a atuação do comitê de TI têm influência direta e positiva na atuação da gestão de portfólio de investimento de TI;

v. Identificar se a utilização do planejamento estratégico de TI têm influência direta e positiva na efetividade da governança de TI.

vi. Identificar se a atuação do comitê de TI de forma indireta, via a gestão de portfólio de investimento de TI, têm influência positiva na efetividade da governança de TI. 


\section{REVISÃO DE LITERATURA}

\subsection{NOVA GESTÃ̃ PÚBLICA}

A Nova Gestão Pública teve seu marco inicial, segundo Denhardt (2008), num seminário acadêmico realizado em 1968 no Centro de Convenções Minnowbrook, na Universidade de Syracuse, em Nova Iorque. Esse seminário reuniu jovens e promissores cientistas no campo da administração pública, com uma visão diversa "das abordagens dos autores mais consagrados no campo". O conjunto da produção desse seminário subsidiou e deu origem ao livro intitulado "Toward a New Public Administration", de autoria de Frank Marini, publicado em 1971, cujo objetivo principal era disseminar práticas para tornar a gestão pública mais eficiente, visando a obtenção de resultados para a sociedade.

As bases da Nova Gestão Pública, conforme Hood (1995), são relacionadas aos seguintes fatores: foco no cidadão, orientação para resultados, por meio do planejamento estratégico e indicadores de desempenho, ênfase na transparência e no controle social, flexibilização da gestão, e valorização e desenvolvimento de pessoas (servidores).

Uma questão muito discutida a respeito do Gerencialismo é a sua implicação relativa às relações de responsabilidades (accountability) para os gestores públicos e desses com servidores, ministérios, secretarias, autoridades políticas, cidadãos, o Poder Legislativo e o Poder Executivo. Na gestão gerencial, o comprometimento com o resultado tornou-se um instrumental que promove os mecanismos de responsabilidade.

Esta relação entre compromisso com os resultados revertidos para o cidadão e a responsabilidade que esta missão se faz operar sobre os políticos e servidores públicos, fez eclodir a ideia de efetividade no contexto do setor público. Esta efetividade para a Nova Gestão Pública, avança em direção a organizações mais flexíveis (diminuição da burocracia), inovadoras e eficientes, cujo foco central do desenho da entrega de serviços públicos passa a 
ser o cidadão (denominado de "cliente"), ao qual é destinado um tratamento mais personalizado.

No caso brasileiro, a Nova Gestão Pública começou a ser implementada, a partir de 1990, no governo do Presidente Fernando Collor de Mello, tendo como estratégia a orientação para: (a) definição clara dos objetivos a serem alcançados pelos administradores públicos em suas unidades, (b) garantia de que o administrador público tenha autonomia na gestão dos recursos humanos, materiais e financeiros disponíveis para atingir seus objetivos e (c) controle a posteriori dos resultados (BRASIL, 1995).

Essas estratégias vieram a se tornar centrais no governo Fernando Henrique Cardoso com a criação do Plano Diretor de Reforma do Aparelho do Estado o qual definiu as diretrizes e estabeleceu os objetivos para a reforma da administração pública, tendo como justificativa a crise do papel do Estado (Ferrarezzi e Amorim, 2007).

\subsection{NOVA GOVERNANÇA PÚBLICA}

Desta forma, a aplicação da gestão de negócios no ambiente público preconizada pela Nova Gestão Pública procurou tornar os serviços prestados pelo governo mais ágeis e responsáveis perante os cidadãos tendo como pontos principais a concorrência, a satisfação do cliente, e medição de desempenho. Estes esforços têm produzido uma variedade de resultados concretos que incluem o aumento da proatividade na resolução de problemas por parte dos gestores públicos (Ammons e Rivenbark, 2008), melhoria nos sistemas de integração de políticas públicas (Wholey, 1999; Hatry, 2002; Moynihan e Pandey, 2005; Hatry, 2010) e a aplicação de medidas de desempenho (Hatry, 2010).

No entanto, há lacunas quando a Nova Gestão Pública faz uso de princípios de negócios do setor privado para melhorar o desempenho do governo, sendo que estas inconsistências são: inexistência de um denominador como "lucro" ou "retorno do 
investimento" (denominadores comuns no ambiente privado) o que dificulta a comparação comum em toda a ampla gama de programas públicos , já que estes são construídos com base na confiança e legitimidade dos cidadãos nas suas instituições políticas e não na eficiência centrada no mercado; contraposição da proposta de movimento em linha reta delineada por metas e objetivos que instrumentalizam e se vinculam as medidas de desempenho com as fragmentadas e diversas estruturas e autoridades que compõem o setor público; a tentativa de usar abordagens administrativas para resolver problemas que são essencialmente de natureza política (Kettl, 2000; Larsen, 2008); e a ênfase sobre a governança de organizações individuais em contraposição a uma busca de uma governança de todo o complexo sistemas de prestação de serviços públicos.

Estas lacunas da NPM têm gerado um contramovimento denominado Nova Governança Pública que coloca os valores políticos no centro do debate em contraposição ao foco estritamente instrumental da Nova Gestão Pública.

A Nova Governança Pública (NPG) coloca muito mais ênfase na participação do cidadão e oferta de serviços sociais do terceiro setor os quais apoiarão o objetivo do governo que está em promover o bem comum mais do que apenas melhorar a eficiência, eficácia, ou a capacidade de resposta na execução de um determinado programa (Moore, 1994, 1995; Alford, 2002; Stoker, 2006). A coprodução é um elemento central da NPG, pois a coprodução promove a mistura de agentes de serviços públicos e cidadãos que contribuem para a prestação de um serviço público. Na NPG há um reconhecimento crescente do envolvimento mais amplo e mais proativo dos cidadãos na definição e prestação dos serviços públicos, pois a política é vista como a expressão mediada de preferências determinadas coletivamente (Moore, 1995; Alford, 2002; O'Flynn, 2007). 


\subsection{A GOVERNANÇA DE TI NA ADMINISTRAÇÃO PÚBLICA}

A implementação da Nova Gestão Pública reforçou a inclusão de medidas que combinassem o atingimento da requerida performance organizacional e a exigência pela aplicação da accountability (Barret, 2003).A exigência pela accountability se torna mais forte com a Nova Governança Pública, pois esta vê os cidadãos como coprodutores que atuam ativamente na prestação de serviços e na tomada de decisão, exigindo uma excelente prestação de serviço (Bovaird, 2007; E Simmons et al., 2007; Powell et al., 2010; Fotaki, 2011). Desta forma, cobra-se mais por uma atividade pública onde a performance está voltada para o melhor atendimento do que foi combinado com o cidadão e da melhoria dos aspectos qualitativos da prestação de serviços em oposição a uma ênfase unilateral sobre a eficiência e o desempenho econômico (Denhardt e Denhardt, 2000; McGuire, 2001; Osborne, 2006).

Logo, este conjunto de medidas solidificou-se na aplicação da governança corporativa pública, pois esta tem, em sua essência, o objetivo de pretender equilibrar a competitividade e produtividade das instituições com uma gestão responsável e transparente da mesma.

A governança corporativa no setor público mira no estabelecimento de uma transparente identificação e articulação das definiçõoes de responsabilidade, além de proporcionar a compreensão real das relações existentes entre as partes interessadas da organização e outros interesses para controlar os seus recursos e dividir resultados. A governança corporativa no setor público também almeja sustentar a gestão, particularmente do nível superior. Por consequência, toda esta gama de alvos da governança corporativa pública também alcança a área tecnológica pública, principalmente pelo seu novo papel no cenário institucional.

Atualmente, a Tecnologia da Informação é considerada ativo crítico e estratégico para as organizações sejam públicas ou privadas. Ambas tem tido altos gastos com TI e 
consequentemente altos benefícios são esperados pelos seus stakeholders (Woodhead, 2004). Portanto, o papel fundamental da TI nas corporações tornam estas cada vez mais dependentes da tecnologia da informação (Gelinas, Sutton e Fedorowicz, 2004).

Na esfera pública, progressivamente, a redução dos custos permitiu que os órgãos governamentais adotassem ferramentas de informática para auxiliar sistemas de pagamento, de armazenamento de dados, além de tarefas rotineiras que passaram a ser automatizadas através da criação de sistemas e aplicações, com vistas a uma maior eficiência na realização dessas atividades (Dunleavy et al., 2006; Holden, 2007). Com o advento da Internet e do modelo da Nova Gestão Pública, surgem discursos no sentido de utilizar a TI de maneira a tornar os órgãos mais responsivos e orientados à prestação de serviços, ao invés de apenas utilizá-la na busca da eficiência.

Este novo conceito fez com que a tecnologia da informação dentro da administração pública envolvesse questões que vão muito além da tecnologia: pessoas, estruturas, processos e sobretudo conhecimento que devem ser articulados para que os recursos de informática de fato respondam adequadamente as aspirações da administração pública e da sociedade (Holden, 2007).

Desta forma, a TI assume a função de um elemento fundamental e transformador da organização pública, deixando de ser objeto apenas de gestão para ser objeto de governança. Assim, a TI pública entra no campo da governança de TI a qual surge, enquanto área de estudo e disciplina prática, como um subconjunto da governança corporativa, logo absorvendo desta os objetivos de gerar valor para o negócio e promover a gestão equilibrada do risco com retorno do investimento a fim de influenciar significativamente no desempenho da organização (Jaeger-Neto et al., 2009).

No aspecto público, a governança de TI vem atender um novo modelo de administração pública que incorpora de vez a tecnologia da informação como elemento-chave 
para atender o objetivo global do setor público, qual seja: prover bens e serviços públicos de qualidade para os cidadãos.

$\mathrm{Na}$ busca por uma definição, a governança de TI pode ser conceituada como uma especificação dos direitos decisórios e do framework de responsabilidades para estimular comportamentos desejáveis na utilização da TI, sendo de responsabilidade da diretoria e da gerência executiva da organização (ITGI, 2004; Weill e Ross, 2006). Outra definição, mais recente, considera a governança de TI como uma estrutura de relacionamentos e processos de TI que dirigem e controlam a organização a fim de atingir os objetivos corporativos (Fergunson et al., 2013).

No caso específico do ambiente público, deve-se considerar que a governança deve seguir o objetivo deste ambiente o qual se baseia em responsabilidades para com o Congresso, com os contribuintes, com a aquisição e distribuição de poder pela sociedade e com as demandas dos cidadãos e dos stakeholders para publicidade dos atos e transparência no serviço público, ou seja, incluem-se atividades as quais não existem no setor privado ou excedem o grau de exigência deste setor (Barrett, 2001; Mello, 2006).

Desta forma, a governança de tecnologia da informação na administração pública se constitui e se solidifica quando é influenciada e respaldada por um variado grupo de stakeholders das organizações os quais estão voltados para a concretização de objetivos sociais, políticos e ideológicos que os justificam e que se limitam ao ambiente em que operam, logo ultrapassando questões operacionais referentes à tecnologia da informação (Almeida e Cruz, 2002). Estes stakeholders são importantes porque eles possuem recursos pelos quais as organizações possuem dependência o que dá a esses stakeholders poder sobre estas organizações (Pfeffer e Salancik, 1978).

Os stakeholders também se mostram relevantes no contexto do processo de planejamento organizacional e no seu gerenciamento (Freeman e McVea, 2001), direcionando 
os objetivos da organização e influenciando a alocação dos recursos e as estratégias que serão realizadas por esta organização para atendimento dos seus objetivos (Frooman, 1999).

Uma amostra da influência dos stakeholders se configurou durante o estabelecimento do Sistema de Administração dos Recursos de Informação e Informática do Governo Federal (SISP). O Decreto $n^{\circ} 99.180$ de 15 de março de 1990, responsável pela reorganização e funcionamento dos órgãos da Presidência da República e dos Ministérios, instituiu o SISP no Brasil, sob a responsabilidade da Secretaria da Administração Federal e sob a anuência e interesse dos stakeholders ligados aos representantes do governo aplicadores das medidas vindas do gerencialismo e dos setores empresariais do ramo da informática os quais seriam os fornecedores dos recursos de informática e de informação para o governo.

Entretanto, vale ressaltar que apesar da força e pressão dos stakeholders, de 1990 até 2010, esse sistema passou por um progressivo processo de institucionalização, através do qual sua organização e suas ações e práticas ganharam valor e estabilidade apenas décadas depois da sua criação (Huntington, 1975; Goodin, 1996).

\subsection{EFETIVIDADE DA GOVERNANÇA DE TI}

A efetividade é um elemento que não apresenta um consenso em torno da sua definição (Cameron, 1986), existindo dificuldades adicionais relacionados às diferenças significativas entre os setores públicos e privados (Hood, 2007; Parhizgari e Gilbert, 2004).

Entre as diversas conceituações, destaca-se a de que a efetividade organizacional pode ser definida como a capacidade de uma instituição corresponder às expectativas dinâmicas e mutantes em relação aos produtos, serviços e resultados gerados no seu próprio contexto, sendo uma medida de mensuração entre o planejado e executado (Cavalieri, Macedo-Soares e Thiollent, 2004). 
Trazendo este conceito para o cenário das TIC's, ressalta-se que elas ganharam importância crescente, pois trouxeram a melhoria da oferta de serviços através da modernização, personalização e autoatendimento construídos no conceito de um governo eletrônico que carrega a ideia da efetividade como princípio básico da ação estatal (Merrien, 1998).

Assim, surge à necessidade de se definir efetividade de TI a qual também se depara com a questão da falta de consenso tal qual a efetividade organizacional/governamental. No entanto, conforme Silva e Moraes (2011), a efetividade de TI pode ser trabalhada na perspectiva de negócio, logo estando voltada aos vínculos entre os resultados da TI e o sucesso organizacional na busca pela compreensão do contexto local e da sua efetividade em uma visão que também engloba o ambiente externo, as características setoriais de cada organização e a estrutura funcional interna.

Para a Governança de TI, deve-se levar em consideração que a efetividade se caracteriza pelo cumprimento de objetivos relacionados a custo, crescimento, utilização de ativos e flexibilidade de negócios (Weill e Ross, 2004), além do cumprimento dos requisitos legais e requisitos regulamentares (Bowen et al., 2007). Segundo Weill e Ross (2006), o atendimento destes objetivos se expressa em uma governança de TI que é efetiva pelo fato de atender aos seguintes fatores críticos: Transparência, Participação ativa, Redesenho frequente, Estabelecimento da governança com atuação em múltiplos níveis organizacionais, Simplicidade, Existência de um processo de tratamento das exceções e Alinhamento nos sistemas de incentivo e recompensa.

Portanto, a construção de uma governança de TI efetiva envolve um conjunto de processos que tenham como propósito a realização das expectativas em relação aos fatores críticos de sucesso para a organização (ISACA, 2011). Logo, a efetividade da governança de TI, tanto nos ambientes público como privado, se dará com a aferição de como a qualidade 
dos resultados originados das estruturas de tomada de decisão, processos e mecanismos relacionais para direção e controle de operações de TI influenciam na realização das metas de TI (Sambamurtht e Zmud, 1999; Torres, 2004) e consequentemente se refletirá nos objetivos organizacionais.

Esta efetividade será alcançada através da atuação de um conjunto de arranjos e práticas associadas à estrutura, processos e relacionamentos (Van Grembergen, De Haes e Guldentops, 2004) os quais atuam de forma a atender os objetivos da organização acerca da tecnologia da informação, possuindo os seguintes significados:

1) Mecanismos de Estrutura - envolvem a organização e o posicionamento da área de TI na estrutura hierárquica da organização, bem como a clara definição de papéis e responsabilidades dos cargos que compõem essa estrutura (De Haes e Van Grembergen, 2008).

2) Mecanismos de Processo - abordam a tomada de decisão estratégica, o planejamento estratégico de TI e os frameworks de monitoramento, controle e processos (De Haes e Van Grembergen, 2008).

3) Mecanismos de Relacionamento - complementam a governança de TI, incorporando as relações da TI com as demais áreas da organização e com seus usuários. Estes mecanismos garantem o funcionamento da estrutura criada para a TI e dos processos estabelecidos (De Haes e Van Grembergen, 2008).

Peterson (2001) foi um dos primeiros a definir um conjunto de mecanismos, identificando seis mecanismos chave e dando exemplos de como eles são implementados nas organizações. Weill e Ross (2004) realizaram um estudo com 256 empresas de diferentes países com o intuito de demonstrar que a implementação de mecanismos de governança de TI pode gerar rentabilidade, principalmente os mecanismos de estrutura de tomada de decisão e relacionamento. 
Ali e Green (2007) utilizaram equações estruturais para examinar 110 questionários respondidos por membros da ISACA na Austrália, sugerindo que há uma correlação positiva e significativa entre o nível geral de efetividade da governança de TI e os mecanismos de relacionamento envolvimento de alta gerência em TI e conjunto de práticas formais/informais de comunicação.

Prasad, Heales e Green (2010) sugerem, em seu estudo, que as empresas que possuem mecanismos de estrutura de governança de TI, como, por exemplo, comitês de direção de TI, possuem níveis elevados de desempenho e uma maior capacidade de gerência sobre os recursos de TI. Já Van Grembergen e De Haes (2009) identificaram trinta e três mecanismos através de múltiplos estudos de caso e da realização de um survey, apresentando vários casos de empresas ao redor do mundo, conectando a teoria e a empiria em relação à implementação dos mecanismos de governança de TI nas organizações.

Em um estudo mais recente, Heindrickson e Santos Jr. (2014) verificaram que é necessária a mediação do Processo de portfólio de investimentos em TI para que sejam estatisticamente significativos os efeitos percebidos de melhorias de desempenho em comitê de TI e em gestor de solução de TI sobre a efetividade da governança.

Ao se debater sobre quais e quantos mecanismos são relevantes para a existência da efetividade da governança de TI, percebe-se que a abordagem holística dos fatores influenciadores da administração pública, os quais foram descritos anteriormente, corrobora com pesquisas da área de governança, pois a abordagem aponta que entre os vários mecanismos de governança de tecnologia da informação listados e documentados, existe apenas uma quantidade restrita que realmente são significativos e podem impactar a efetividade da governança tecnológica pública.

Mostrando algumas destas pesquisas que chegam a esta dedução, De Haes e Van Grembegen (2008) concluíram que existem cinco práticas que são mais eficazes comparadas a 
outras, como por exemplo, os comitês de direção de TI e o gerenciamento de portfólio, sendo que esta pesquisa foi feita no setor financeiro belga. Já com a realização de um estudo de caso em uma organização de grande porte, Bowen, Cheung e Rohde (2007) exploraram os fatores que influenciam os mecanismos de governança de tecnologia da informação, indicando em seus resultados que o desempenho de governança de TI está associado a mecanismos como a compreensão compartilhada dos objetivos entre negócio e a TI, o envolvimento ativo dos comitês de TI na direção e decisões, estratégias e políticas compartilhadas e comunicadas entre negócio e TI.

Voltando ao campo do cenário proposto, verifica-se que a dupla stakeholders / ideias dos modelos Nova Gestão e Governança Pública são componentes que estão incluídos na construção da estratégia organizacional e da governança tecnológica pública, sendo que a formação e implantação desta estratégia exerce uma importante influência no desempenho das instituições (Miles e Snow, 1978). Esta dupla também se faz importante ao analisar fatores ligados à liderança, pois se verifica que a falta de compromisso da alta administração com os princípios estratégicos nas organizações acaba por promover o esvaziamento do planejamento e organização em longo prazo, sobrecarregando as chefias intermediárias, além de causar a falta de alocação de recursos financeiros para apoiar a implantação das definições estratégicas (Hackler e Saxton, 2007; Andrews, Boyne, Law e Walker, 2009; Abbasi e Shahamati, 2011).

Logo, considerando a abordagem dos fatores influenciadores da implantação da governança de TI na administração pública federal já relatada neste trabalho, observa-se que existe um número restrito e específico de mecanismos de governança que são necessários e suficientes para serem testados com relação a sua capacidade de impactar a efetividade governança de TI na administração pública. Estes mecanismos também se caracterizam por carregarem as características de serem influenciadores, ou seja, são instrumentos geradores de medidas para a efetiva implantação da governança tecnológica dos órgãos públicos. 
Por conseguinte os mecanismos acima relatados os quais terão sua importância descrita a seguir são:

1) Mecanismo de Relacionamento - Suporte da alta administração (inclui os mecanismos de reuniões informais entre negócios e TI de gestão executiva/sênior e executivo/gerência sênior dando o bom exemplo) - o comprometimento da alta administração com as iniciativas relacionadas a governança de TI aumenta o sucesso da TI, sendo um compromisso que também ajuda a integra-lá com as estratégias, processos de negócios, expectativas dos stakeholders e mecanismos institucionais que garantam a continuidade dos investimentos em TI ao longo tempo (Armstrong e Sambamurthy, 1999). Este mecanismo por sua alta influência e poder, se constitui como mecanismo gerador de outros "mecanismos" de estrutura, processos e relacionamento.

2) Mecanismo de Estrutura - Comitê de TI (possui especializações como, por exemplo, os comitês de priorização de projetos, comitê de segurança de TI e o comitê de arquitetura de TI) - Por determinar os métodos e as formas de gestão e as prioridades de investimento de negócios de TI, este mecanismo também tem caráter gerador tal qual o anterior e detém a missão de gerir os recursos oriundos justamente das partes interessadas (De Haes e Van Grembergen, 2009).

3) Mecanismo de Processo - Gestão de portfólio de investimentos de TI - Inclui processos de priorização, investimentos e projetos em que os negócios e a TI estejam envolvidas, sendo sua construção e existência vinculada ao mecanismo de comitê de direção de TI (De Haes e Van Grembergen, 2009; Heindrickson e Santos Jr., 2014). O gerenciamento de portfólio e o comitê de direção de TI são pontos de contatos para o exercício do poder dos stakeholders na medida em que nestas áreas é que ocorrem o controle da disponibilização de recursos e o resultado 
que a organização devolve após a utilização destes recursos os quais são oriundos das partes interessadas (Frooman, 1999).

4) Mecanismo de processo - Planejamento estratégico de TI - se trata de um processo formal para definir e atualizar a estratégia de TI e que concentra todos os métodos, processos e implementações necessárias para que a TI atenda com sucesso as estratégias organizacionais (Lederer e Sethi, 1988). Logo, por ter um caráter orientador, várias ações (ou “mecanismos”) são derivados do seu planejamento.

Portanto, os mecanismos, os quais possuem caráter não operacional direcionador, a serem trabalhados neste estudo são: Suporte da Alta Administração (Mcgee e Prusak, 1994; Davenport, 2001; Beal, 2004; Siqueira, 2005); Atuação do Comitê de TI (ITGI, 2003; Luftman e Brier, 1999; Weill e Ross, 2004; De Haes e Van Grembergen, 2006; Heindrickson e Santos Jr., 2014); Atuação da Gestão de Portfólio de Investimentos de TI (De Haes e Van Grembergen, 2006; Heindrickson e Santos Jr., 2014); Utilização do Planejamento Estratégico de TI (Earl, 1993; Rockart, 1979; Hammer e Champy, 1993; De Haes e Van Grembergen, 2006).

Portanto, além da efetividade de governança de TI já descrita anteriormente, a seguir serão relatados as demais variáveis com seus respectivos conjuntos de hipóteses, além da apresentação das razões que levaram ao estudo e a escolha destes quatro mecanismos.

\subsection{SUPORTE DA ALTA ADMINISTRAÇÃO}

A literatura tem enfatizado a importância do mecanismo de relacionamento denominado suporte da alta administração para o sucesso de qualquer atividade organizacional (Rockart e Scoot-Morton, 1984; Jackson,1986; Raghuntathan e Raghunathan, 1990; Luftman, Papp e Brier, 1999, Bowen et al., 2007). Um estudo feito por Luftman et al. 
(1999), envolvendo uma aplicação de questionário para 500 empresas e executivos de TI com o objetivo de determinar os facilitadores e inibidores do alinhamento das estratégias de negócio e de TI, revelaram que o apoio de alta administração foi considerado o mais importante facilitador do alinhamento entre negócio e TI.

Seguindo esta mesma lógica, as práticas de governança de TI ganharam maior visibilidade nas organizações como uma possível forma de atender as expectativas da alta administração da organização (Prasad, Heales e Green, 2010; Mahoney, 2012) incluindo o abastecimento de recursos organizacionais que permitissem identificar os riscos que são relacionados ao negócio. Todavia, para que toda esta rede de benefícios se manifeste, cabe à própria alta administração a formulação da estratégia e seu desdobramento em uma série de "decisões organizacionais", assumindo a responsabilidade pelas políticas globais da organização e naturalmente se tornando um fator crítico para a efetiva implantação das políticas voltadas para governança de TI. A alta administração tem por obrigação tornar adequada a comunicação dessas políticas estratégicas da organização as quais conduzirão ao alinhamento organizacional do negócio com a TI (De Haes e Van Grembergen, 2009; Henderson e Venkatraman, 1993; Luftman, 2000).

Desta forma, o suporte da alta administração possibilita vencer as resistências culturais incrustadas nas organizações públicas, revertendo esta desconformidade, além de permitir a capacitação para a elaboração e a prática dos planejamentos estratégicos que orientarão toda a organização. Com o apoio da alta administração para a governança, indutivamente serão estabelecidos formalmente os objetivos institucionais de TI, os indicadores para cada objetivo, as metas para cada indicador e os mecanismos que a alta administração adotará para acompanhar o desempenho da TI da instituição (BRASIL, 2010).

Assim, o suporte da alta administração se constitui como um mecanismo gerador de diversas ações que são também entendidas como mecanismos, como por exemplo, a exigência 
da atuação do gestor de solução de TI como um defensor da governança e também a elaboração e manutenção de diversas ações de relacionamento (rotação de trabalho, colocation, cross-training, gestão do conhecimento, comunicação corporativa e campanhas de sensibilização de governança de TI).

Todo este poder e influência deste mecanismo na geração de ações a favor da governança tecnológica ocorrem pelo fato de que a alta administração tem a função integradora da tomada de decisão o que a torna responsável por proporcionar o entendimento e o aprendizado mútuo entre o negócio e a TI, além de ser um canal que representa a participação ativa dos stakeholders (Peterson, Callaghan e Ribbers, 2000). Ressalta-se que pode existir o efeito contrário caso exista a falta de apoio da alta direção, pois isto representa a falta de apoio dos stakeholders no processo, o que pode acarretar em efeitos negativos sobre o desempenho, mesmo quando são feitos investimentos substanciais para adquirir ou desenvolver tecnologia (Wade e Hulland, 2004).

Portanto, levanta-se a seguinte hipótese:

H1: O suporte da alta administração tem influência direta e positiva na efetividade da governança de TI.

\subsection{ATUAÇÃO DO COMITÊ DE TI}

A literatura preconiza a existência do mecanismo de estrutura comitê de TI, também denominado comitê de direção de TI, como um eficaz mecanismo de governança de TI (ITGI, 2004), pois a existência e o funcionamento eficaz desta comissão, particularmente na atuação para o planejamento e o alinhamento das responsabilidades para com os negócios, são fundamentais para a manutenção das estruturas de governança, gerenciamento e planejamento dos processos e dos sistemas de informação (Steiner, 1979; Doll, 1985; Doll e Torkzadeh, 1987; Earl, 1989; Gupta e Raghunathan, 1989; Ragunathan e Ragunathan, 1989; ISACA, 
2011). Weill e Ross (2006), a partir de estudos que avaliaram empresas internacionais de grande porte, relataram que Comitês de direção de TI são um importante mecanismo de governança utilizado pelas empresas que apresentam melhor desempenho. O comitê é composto por um time de executivos de diversas áreas da organização com a principal função de conectar as estratégias de negócio e de TI, além de tomar decisões quanto à seleção e priorização de projetos (Nolan, 1982; McKeen e Guimaraes, 1985; Moraes e Laurindo, 2003; Castro e Carvalho, 2010).

Portanto, quando o comitê é constituído e representado pelos stakeholders participantes do controle e do fornecimento de recursos institucionais (Frooman, 1999), consegue-se gerir os itens regulatórios (Jacobson, 2009), levando a atenuação das perdas de agência e ao fornecimento de incentivos aos funcionários para agir da maneira exigida pela organização, além de monitorar se a TI está contribuindo para o alcance dos planos e objetivos organizacionais (Gupta e Raghunathan, 1989; Raghunathan e Raghunathan, 1989; Bowen et al., 2007; De Haes e Van Grembergen, 2008).

Analisando o papel do comitê de TI em controlar os recursos organizacionais, Earl (1989) alega que uma das principais funções deste comitê está em criar políticas e procedimentos associados com o controle da tecnologia da informação. Assim, imbuído deste papel, o comitê cria medidas que reduzem a probabilidade de potenciais brechas dentro do ambiente tecnológico organizacional, que caso não fossem realizadas, permitiriam a exploração pejorativa de recursos da organização.

Também se detectou que o comitê de direção de TI atua na gestão de portfólio especialmente nas fases de priorização, autorização e revisão dos investimentos a serem realizados (Archer e Ghasemzadeh, 1999; De Haes e Van Grembergen, 2008; Heindrickson e Santos Jr., 2014). Pautado no modelo de governança de TI baseado no stakeholder, detecta-se que nesta atuação entre o comitê e a gestão de portfólio ocorre a expressão do direcionamento 
dos stakeholders e o cumprimento da legitimidade das ações dentro das organizações. Isto acontece porque são nestes mecanismos onde existe a manifestação da forma de alocação/controle dos recursos de TI e o tratamento de como será conduzido o trade-off entre a rentabilidade/eficiência do custo e o crescimento sustentável, confiável e estável da TI (Korac-Kakabadse e Kakabadse, 2001).

De forma adicional, o trabalho do comitê se perfaz de fator gerador de ações ou "mecanismos" derivados que atuam na melhoria da governança, tais como, os comitês especializados (auditoria, segurança, arquitetura, priorização de projetos e estratégia).

Ressalta-se que a escolha do mecanismo se originou principalmente do estudo de Heindrickson e Carlos Jr. (2014) os quais investigaram tanto os efeitos diretos da atuação do comitê quanto os indiretos, através da gestão de portfolio, no impacto da efetividade da governança de TI em instituições públicas brasileiras.

Desta forma, surgem as hipóteses a seguir:

H2: A atuação do comitê de TI tem influência direta e positiva na efetividade da governança de TI.

H3: O efeito total da atuação do comitê de TI em efetividade da governança de TI é positivo, ou seja, o saldo dos efeitos diretos e dos efeitos indiretos via processo de gestão de portfolio, da atuação do comitê de direção de TI em efetividade é positivo.

H4: A atuação do comitê de TI tem influência direta e positiva na atuação da gestão de portfólio de investimentos em TI.

\subsection{ATUAÇÃO DA GESTÃO DE PORTFÓLIO DE INVESTIMENTOS DE TI}

O mecanismo de processo de gestão de portfólio de investimentos de TI existe com o objetivo de aperfeiçoar o uso dos recursos institucionais, de modo a selecionar um conjunto de projetos e programas que produza o maior retorno possível à organização (De Haes e Van 
Grembergen, 2006). Vale ressaltar que os projetos e programas selecionados precisam estar alinhados com as estratégias corporativas e o processo de gestão deve estar congruente com os objetivos das chamadas áreas-foco da Governança de TI: alinhamento estratégico, entrega de valor, gerenciamento de recursos, gestão de riscos e mensuração de desempenho (ITGI, 2007).

Weill, Woerner e Rubin (2008) verificaram o desenvolvimento da gestão de portfólio na governança de TI por empresas de grande porte internacionais, enquanto Moraes e Laurindo (2003) fizeram esta análise no cenário nacional e ambos mostraram resultados positivos com a implantação deste mecanismo. O trabalho de Heindrickson e Santos Jr. (2014), o qual foi o estudo gerador da inclusão do mecanismo de gestão de portfólio de investimentos de TI, também detectaram uma influência positiva desta gestão de recursos na efetividade da governança tecnológica, mas no caso eles se detiveram em instituições públicas federais brasileiras. Assim, com base nestas informações, podem-se construir a seguinte hipótese:

H5: A atuação da gestão de portfólio de investimentos de TI tem influência direta e positiva na efetividade da governança de TI.

\subsection{UTILIZAÇÃO DO PLANEJAMENTO ESTRATÉGICO DE TI}

Com o crescimento do investimento em TI e sua ascensão quanto área de apoio às estratégias de negócio e/ou área criadora de possibilidades estratégicas, se tornou quase que axiomático a premissa de que a gestão de sistemas de informação depende de um mecanismo de processo denominado planejamento estratégico de TI. Esta premissa é levantada porque o instrumento visa atender os objetivos de alinhar os investimentos em TI com os objetivos da organização, direcionar a gestão eficiente e eficaz de recursos e desenvolver políticas e 
arquiteturas tecnológicas (Synott e Gruber, 1982; Earl, 1988; Henderson e Venkatraman, 1989; Earl, 1993).

Desta forma, o planejamento estratégico de TI pode ser definido como um processo decisório formal que define e atualiza a estratégia de TI e identifica potenciais aplicações que a organização deve implementar (Lederer e Sethi, 1988; Van Grembergen e De Haes, 2009), sendo que a implantação e o atendimento dos objetivos e metas estabelecidos neste planejamento constituem a essencialidade do cumprimento dos critérios utilizados para monitorar e dar entendimento entre os resultados dos processos da área de TI e os objetivos estratégicos da organização.

Este mecanismo possui característica direcionadora porque gera e congrega ações (também incluídas na literatura como mecanismos) que se traduzem em métodos (tais como, frameworks de governança de TI e projetos de governo/metodologias de gestão), processos (como os procedimentos calcados nos acordos de níveis de serviço e em elaboração de relatórios das entregas e benefícios) e implementações (tais como os sistemas de medição de desempenho e controle/relatórios de orçamentos) que colocados na programação de atividades e aplicados na governança tecnológica, consequentemente levarão ao sucesso do próprio planejamento estratégico de TI (Lederer e Sethi, 1988).

Logo, com as informações anteriormente apresentadas, ergue-se a hipótese abaixo:

H6: A utilização do planejamento estratégico de TI tem influência direta e positiva na efetividade da governança de TI.

\subsection{MODELO CONCEITUAL}

Desta forma, com base em tudo que foi relatado, segue o modelo que resume o tema abordado com suas variáveis, relações e hipóteses a serem estudadas e testadas, pontuando que os mecanismos em azul são aqueles que foram extraídos do modelo trabalhado por 
Heindrickson e Santos Jr. (2014) e os em amarelo foram retirados de um estudo exploratório feito por De Haes e Van Grembergen (2009):

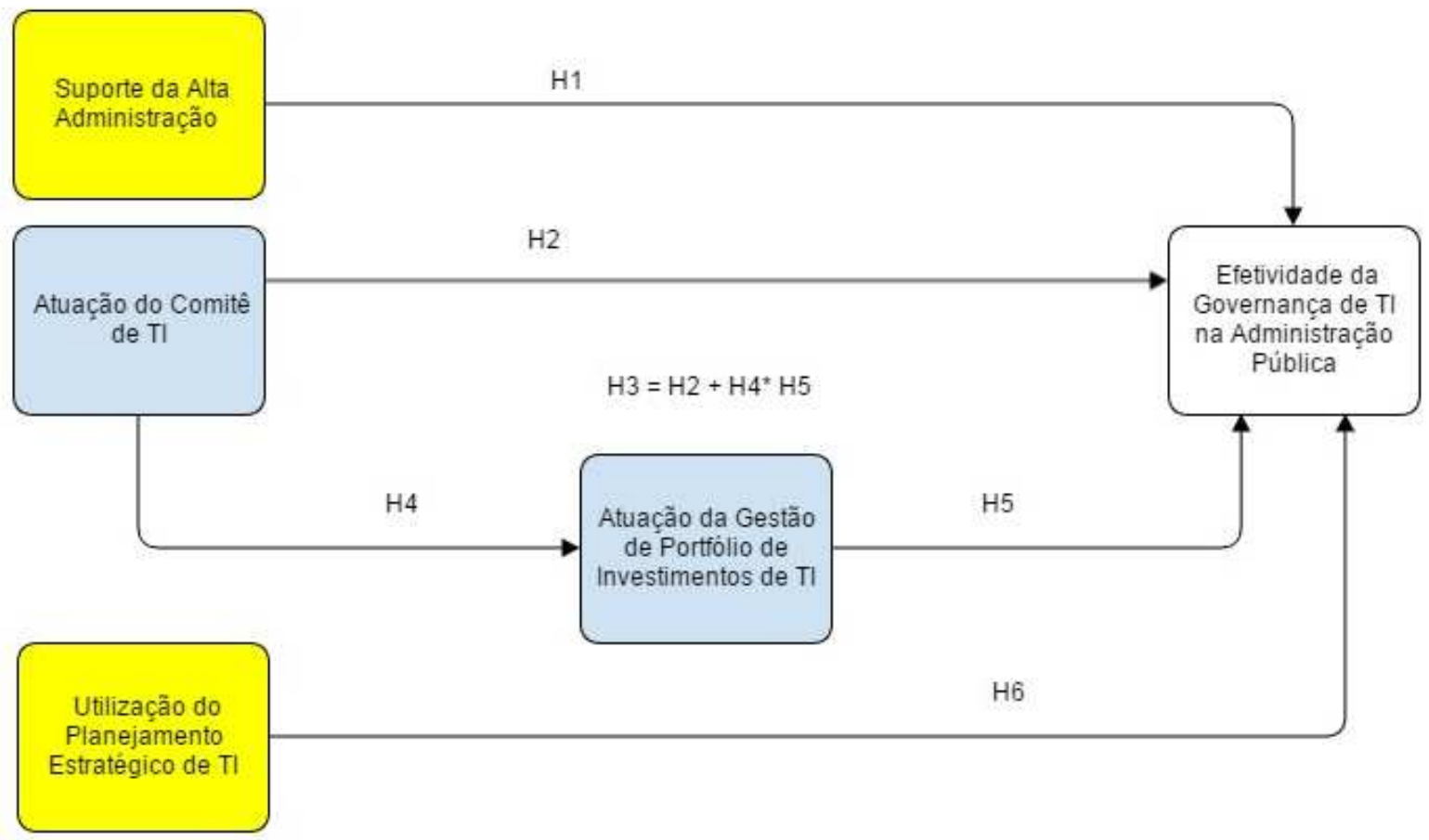

Figura 1. Modelo conceitual e hipóteses. Fonte: elaborada pelo autor, com base em De Haes e Van Grembergen (2009) e Heindrickson e Santos Jr. (2014). 


\section{METODOLOGIA DA PESQUISA}

O capítulo abordará os aspectos metodológicos utilizados neste trabalho, sendo a sua divisão composta da seguinte forma: no subcapítulo 3.1 serão apresentadas as características da pesquisa; o subcapítulo 3.2 discorrerá sobre o universo e a amostra; e o subcapítulo 3.3 abordará os procedimentos de coleta, de tratamento e de análise dos dados da pesquisa.

\subsection{CARACTERÍSTICAS DA PESQUISA}

Esta pesquisa possui como principal característica a utilização de técnicas de coleta e análise de dados do tipo quantitativo. Uma pesquisa científica pode ser considerada um processo dinâmico e evolutivo composto por etapas relacionadas entre si e um objetivo comum (Sampieri, Collado, Lucio, 2006). Assim, a metodologia foi dividida em duas fases distintas para facilitar a sua gestão, tendo cada uma das fases da pesquisa como resultado o marco para o início da fase seguinte. A integração dos resultados obtidos em cada estágio da pesquisa contribuiu para a obtenção dos resultados finais deste estudo.

Na primeira fase, realizou-se uma pesquisa de campo, de natureza quantitativa, por meio do levantamento de opiniões a partir da aplicação de um questionário no universo da Administração Pública Federal, o que tornou o trabalho ainda mais complexo pela dificuldade quanto ao acesso aos executivos da governança de Tecnologia da Informação - TI, o qual foi o perfil de respondentes almejado na pesquisa. Com este levantamento por meio do questionário, mira-se na chance da descoberta e da compreensão do fenômeno sob a perspectiva da percepção das pessoas nele envolvidas (Merriam, 2002).

Na segunda fase, houve a continuação da abordagem quantitativa, pois foi aplicada sobre os dados coletados a técnica estatística denominada equações estruturais para a análise das respostas dos participantes. 
Quanto aos fins e à natureza, o trabalho tem caráter explicativo com recorte temporal transversal, descritivo e aplicado, pois busca-se nas relações de casualidade um resultado tendo como principal objetivo à descrição de algo que normalmente são características ou funções do mundo real (Malhorta, 2001), além de descobrir e observar fenômenos, procurando descrevê-los, classifica-los e interpretá-los (Mattar, 1999). Estes achados miramse em contribuir para a análise da governança de TI na Administração Pública Federal no Brasil.

Desta forma, esta investigação científica objetiva compreender a natureza ambígua de determinados problemas, procurando obter um melhor entendimento das dimensões envolvidas, sem, no entanto, pretender produzir uma evidência conclusiva (Zikmund, 1997).

\subsection{UNIVERSO DA PESQUISA}

A escolha do universo da pesquisa se baseia primordialmente na ideia de que, com base na Nova Gestão Pública e na Nova Governança Pública, o governo deve passar por uma reforma que tem a missão anunciada de aumentar a eficiência da máquina pública, de melhorar a gestão dos recursos disponíveis e de aumentar a transparência da gestão, o que consequentemente influenciou o Plano Diretor de Reforma do Aparelho do Estado elaborado no Brasil (Diniz et al, 2009).

Esta influência calcada na eficiência levou o Plano a determinar, em quatro grupos distintos (Núcleo Estratégico, Atividades Exclusivas, Serviços Não Exclusivos e Produção de Bens e Serviços para o Mercado), as atividades que devem ser exercidas pelo Estado e, para cada grupo, a forma de administração mais apropriada a ser implementada.

Neste caso, o trabalho se concentrará nos grupos que envolvem atividades realizadas exclusivamente pelo Estado, ou seja, o foco estará em organizações que estão no núcleo estratégico e nas atividades exclusivas. 
O núcleo estratégico é o setor que define as leis e as políticas públicas, e cobra o seu cumprimento, sendo responsável pelas tomadas das decisões estratégicas. Correspondem aos Poderes Legislativo e Judiciário, ao Ministério Público e, no Poder Executivo, ao Presidente da República, aos Ministérios responsáveis pelo planejamento e pela formulação das políticas públicas (BRASIL, 1995).

Já as atividades exclusivas abrangem os setores em que são prestados serviços que só o Estado pode realizar. São serviços em que se exerce o poder extroverso do Estado, como os poderes de regulamentar, fiscalizar, fomentar, sendo exemplificado pela cobrança e pela fiscalização dos impostos, a polícia e a previdência social básica (BRASIL, 1995).

Desta forma, dentro deste universo, delimitou-se que a amostra seria formada por gestores da área de TI e profissionais experientes na área de governança de TI dos diferentes tipos de organizações que compõem estes grupos do cenário público federal brasileiro.

\subsection{PROCEDIMENTOS DE COLETA, TRATAMENTO E ANÁLISE DOS DADOS}

O questionário (Anexo I) foi empregado mediante o envio da carta de apresentação eletrônica (Anexo II). Este questionário foi construído utilizando-se a ferramenta Google Docs, sendo suas questões elaboradas com fundamento nos objetivos, nas atividades e nos resultados dos mecanismos de governança estudados e nas características da efetividade de governança de TI, sendo ambos pautados em estudos acadêmicos e nas melhores práticas de governança de TI (Mcfarlan, 1981; Ward, 1990; Jarvenpaa, Ives, 1991; Goodhue, Thompson, 1995; Archer, Ghasemzadeh, 1999; Karimi et al, 2000; ITGI, 2003; Moraes, Laurindo, 2003; Vaswani, 2003; Gao, 2004; Weill, Ross, 2006; ITGI, 2007; Weill, Woerner, Mcdonald, 2009; Castro, Carvalho, 2010; ISACA, 2011; Ali, Green, 2012; Heindrickson, Santos Jr., 2014).

Ressalta-se que a escolha das questões oriundas de trabalhos anteriores foram selecionadas utilizando-se os seguintes critérios: 
1) relação clara, objetiva e concisa entre o conteúdo da questão e o mecanismo a ser avaliado; e

2) verificação com participantes da fase do pré-teste e alguns respondentes do início da aplicação do questionário quanto à dificuldade de entendimento dos itens do questionário.

Com estes critérios adotados, formou-se o questionário definitivo com 19 itens, que apresenta a seguinte divisão: as questões de 1 a 7 são de caráter demográfico, as quais estão focadas no perfil do respondente; as questões de 8 a 10 estão relacionadas ao mecanismo Suporte da Alta Administração; as questões de 11 a 13 se relacionam ao mecanismo Utilização do Planejamento Estratégico de TI; e as questões 14 e 15 abordam sobre a Atuação do Comitê de TI. Já os itens 16 e 17 apontam para o mecanismo Atuação da Gestão de Portfólio de Investimentos de TI, enquanto as questões 18 e 19 tratam da Efetividade da Governança de TI na Administração Pública.

As questões continham respostas em escala Likert (Não sabe/ Não responde, Discordo totalmente, Discordo, Nem concordo nem discordo, Concordo, Concordo totalmente). Porém, foram desconsiderados os servidores que responderam no mínimo um item "Não sabe/Não responde", pois a amostra da pesquisa busca envolver respondentes que de fato tenham maior habilidade e experiência no tema governança de tecnologia da informação, ou seja, pessoas que sempre tenham opinião ou experiência no tocante aos atributos específicos do assunto. No total, 26 pesquisados foram retirados da pesquisa.

Além da definição do questionário, também foi definido que a técnica de equações estruturais seria o método de análise multivariada, a ser aplicada com o objetivo de averiguar a aderência entre o modelo proposto e os casos das organizações públicas pesquisadas.

A Modelagem de Equações Estruturais é um conjunto de técnicas e procedimentos que abordam uma extensão de outras técnicas multivariadas, avaliando as relações de dependência 
entre uma ou mais variáveis, representando as que não podem ser medidas diretamente por meio de outras variáveis denominadas construtos latentes.

Detalhando a explicação, além das latentes, existem as variáveis observadas (manifestas) que são medidas diretamente. Tanto as variáveis latentes como as manifestas podem ser classificadas como exógenas (independentes) e endógenas (dependentes). Os atributos exógenos causam flutuações em outras variáveis no modelo, não sendo explicados por fatores do modelo proposto, pois são influenciados por fatores externos ao modelo. Já os endógenos são influenciados pelos exógenos ou por outros endógenos e a oscilação destas variáveis é influenciada por variáveis presentes no modelo.

No caso deste trabalho, os 12 itens do questionário são variáveis observadas e exógenas, enquanto os mecanismos de governança de TI que compõem o modelo, mais a efetividade de governança de TI, são latentes e endógenas.

As associações destas variáveis podem ser avaliadas a partir da covariância e estão discriminadas no modelo linear, o qual pode ser separado em dois: modelo de medida, que faz a ligação entre o instrumento de medida (variáveis observadas) e o construto teórico (variáveis latentes); e modelo estrutural, o qual define as relações casuais ou de associação entre variáveis e os construtos não observados (variáveis latentes), especificando se uma variável latente causa mudanças em outras variáveis latentes no modelo de forma direta ou indireta. Abaixo segue o modelo estrutural/medida de acordo com a representação gráfica da modelagem de equações estruturais: 


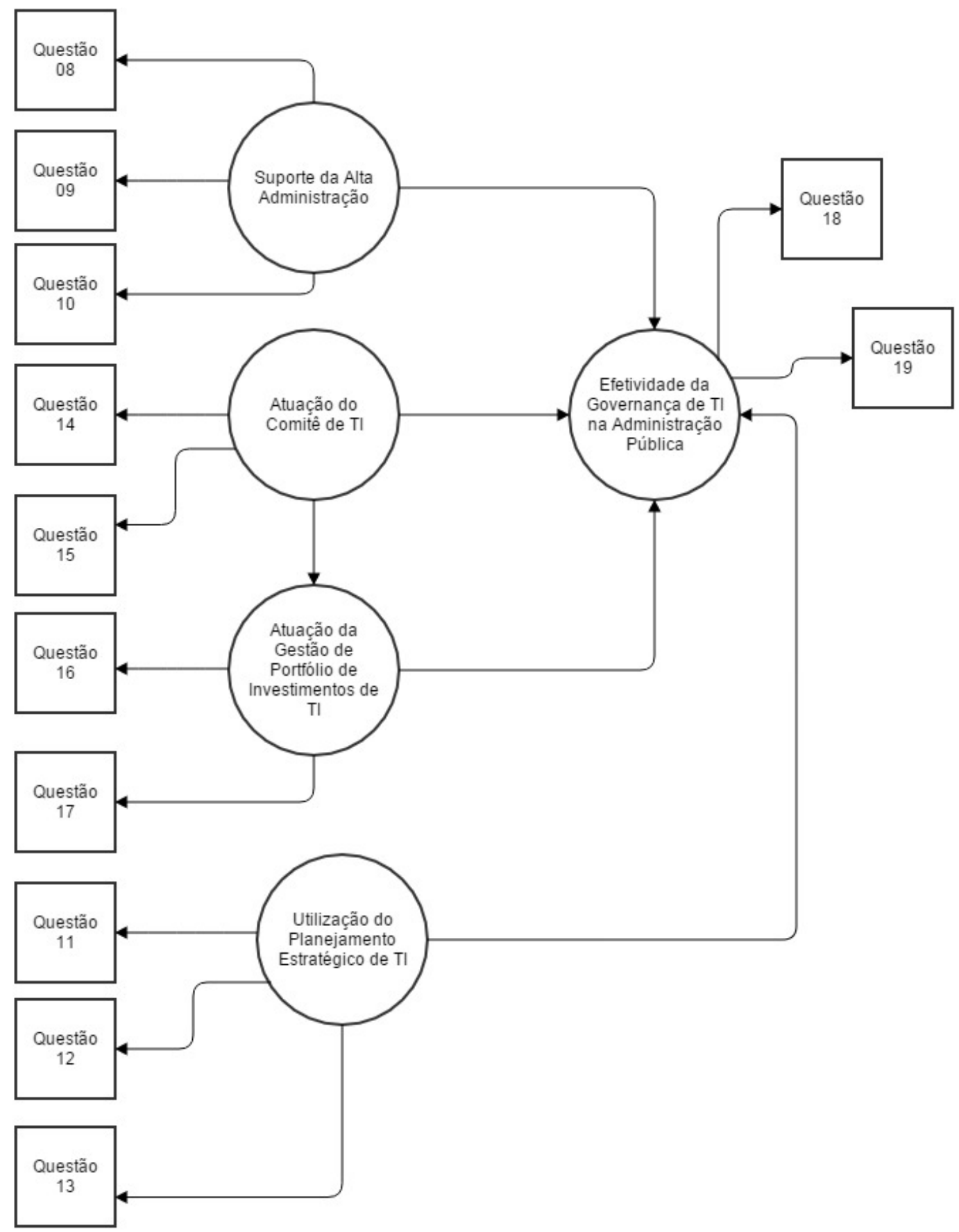

Figura 2. Modelo estrutural/medida e hipóteses. Fonte: elaborada pelo autor, com base em De Haes e Van Grembergen (2009) e Heindrickson e Santos Jr. (2014).

Desta forma, com o modelo construído, foi realizada a programação (Anexo III) no software livre de estatística $\mathrm{R}$ com o apoio do pacote lavaan (sigla em inglês para análise de variáveis latentes) para a efetivação do diagnóstico do modelo e para a conclusão do teste de hipóteses proposto por esta pesquisa. 


\section{RESULTADOS}

Este capítulo dedica-se à apresentação dos resultados da pesquisa bem como às respectivas análises e interpretações dos dados coletados. O capítulo se divide da seguinte forma: no item 4.1 serão descritas as características da amostra e do modelo; no item 4.2 será mostrada a conclusão dos testes de hipóteses.

\subsection{CARACTERÍSTICAS DA AMOSTRA E DO MODELO}

Durante a coleta de dados, foram enviados convites por meio de mensagens eletrônicas, havendo, no resultado final, excluídos os 26 respondentes comentados anteriormente, a participação de 137 servidores de 58 organizações públicas federais, os quais são gestores da área de TI, profissionais experientes na área que trabalham e/ou entendem do tema. O período da coleta ocorreu entre a segunda quinzena de junho a primeira quinzena de novembro de 2015 .

Sobre o tamanho da amostra, cumpre escrever que esta atendeu à regra de tamanho amostral que se baseia no princípio de que o tamanho da amostra deve ter o valor mínimo de dez casos por item (variável manifesta) presente no questionário (Nunnally, 1967; Everitt, 1975), ou seja, para este trabalho, deve-se ter a quantidade mínima de 120 participantes.

A pesquisa garantiu a confidencialidade dos respondentes, focando na percepção que estes possuem sobre a conexão entre os mecanismos de governança de TI e a efetividade desta governança em suas organizações.

No gráfico abaixo, é apresentado o perfil das instituições. 


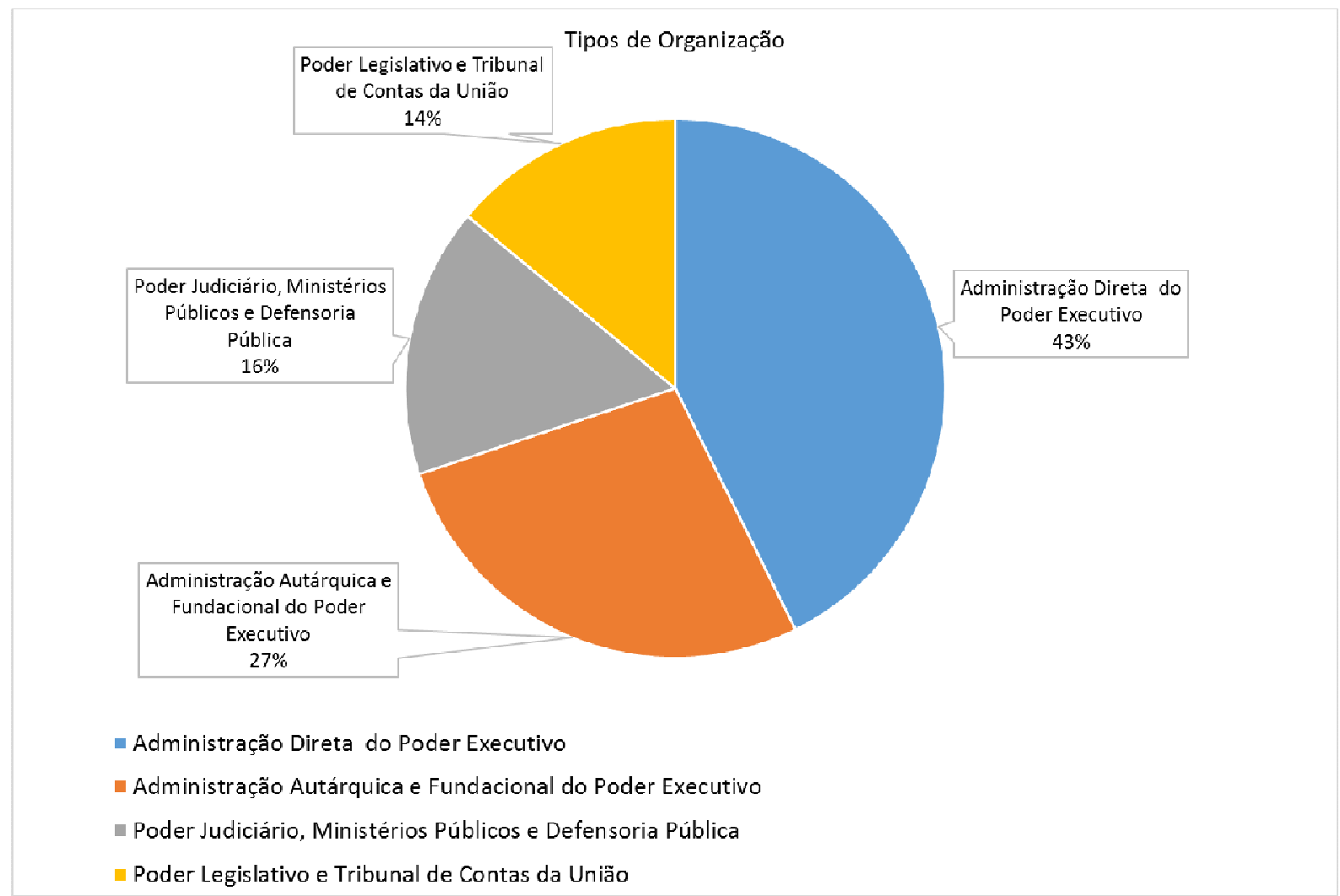

Figura 3. Gráfico sobre os tipos de organização que participaram da pesquisa. Fonte: Dados da pesquisa.

Sobre o perfil dos entrevistados, $84,47 \%$ são do sexo masculino, $36,5 \%$ dos respondentes têm entre 30 e 39 anos, seguidos da faixa etária de 40 a 49 anos, com 30,66\% dos pesquisados. Em relação ao nível de escolaridade, prevalece a Especialização com $54,74 \%$ e o Mestrado com 24,09\% dos respondentes. No gráfico abaixo, apresenta-se o tempo de serviço destes profissionais em sua instituição. 


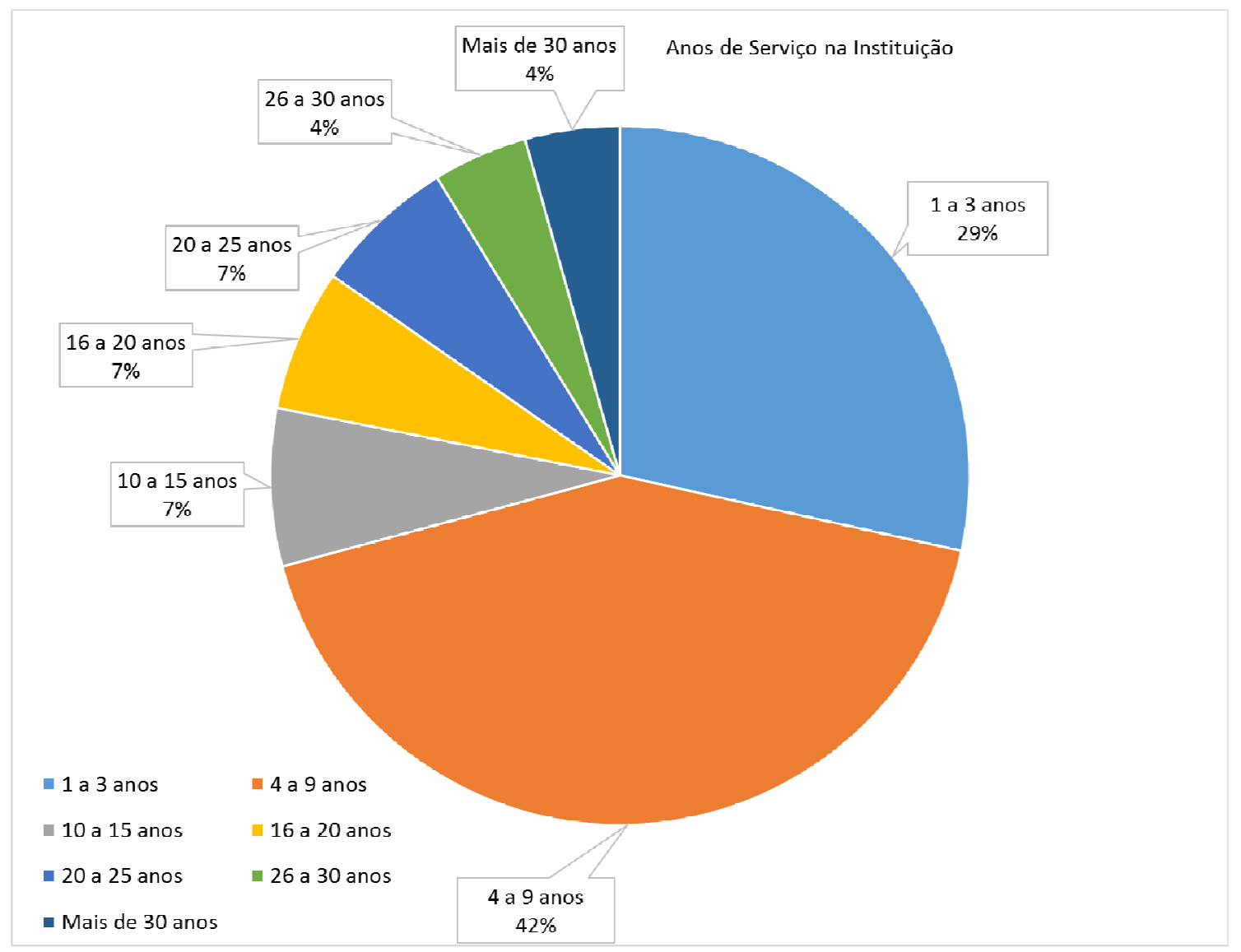

Figura 4. Gráfico sobre o tempo de serviço dos respondentes dentro da instituição. Fonte: Dados da Pesquisa.

Com estes dados, mais os modelos conceitual e estrutural, passou-se à etapa de análise feita por meio da programação (Anexo III) construída no software livre de estatística R. Esta análise inicial se divide em duas etapas: estudo da identificabilidade do modelo e dos índices que revelam o ajustamento global do modelo.

A identificabilidade do modelo está relacionada à necessidade de que a quantidade de informação não redundante seja superior ao número de parâmetros a estimar. Quando isto ocorre, os graus de liberdade são positivos e consequentemente o modelo pode ser estimável.

No caso de modelos com variáveis latentes e mensuração combinados, como o modelo proposto neste trabalho, a identificabilidade é encontrada a partir da aplicação da regra t e da regra de dois passos. 
A regra t é uma condição necessária, mas não suficiente para a condição de identificação de modelos de equações estruturais, em que, possuindo o número de variáveis manifestas endógenas (p), manifestas exógenas (q) e o número de parâmetros livres do modelo $(\mathrm{t})$, se observa o cumprimento da condição na qual t deve ser menor que $[(p+q)$ $*(\mathrm{p}+\mathrm{q}+1)] / 2$.

Sendo, $\mathrm{p}=0$ e $\mathrm{q}=12$, ocorrerá $\mathrm{o}$ estabelecimento da identificabilidade enquanto o número de parâmetros livres for menor que $78(\mathbf{t}<\mathbf{7 8})$. A construção dos grupos de equações matriciais com as suas matrizes de variâncias e covariâncias (Anexo IV) apontam para 31 parâmetros livres $(31<78)$, portanto o modelo a princípio é superidentificável, ou seja, há menos parâmetros a serem estimados do que informação redundante. Isto resulta em um grau de liberdade de valor $47(\mathbf{g l}=\mathbf{7 8}-\mathbf{3 1}=\mathbf{4 7})$, o que reforça a superidentificabilidade atendida na regra t.

Mas, para chegar a este número, adotou-se a regra da variável marcada, assumida também pelo software R, no qual exige-se que uma carga fatorial de cada variável latente seja restrita a um determinado valor (usualmente de 1,0). Este ato promoveu a diminuição dos parâmetros livres que necessitam ser estimados. Neste trabalho, foram escolhidas as questões introdutórias de cada mecanismo avaliado para que estas recebessem a carga fatorial restrita ao valor 1,0 .

Em relação à regra dos dois passos, esta é composta de duas partes, sendo uma condição suficiente, mas não necessária para a condição de identificação de modelos de equações estruturais. Na primeira parte, o modelo é tratado como sendo simplesmente um modelo de análise fatorial confirmatória, sendo aplicada a regra dos dois itens, que é uma alternativa para modelos com mais de uma latente exógena, o que é o caso do modelo descrito neste trabalho. 
De acordo com esta regra, o primeiro passo do modelo é identificável, pois atende às seguintes especificações: a matriz $\Theta \delta$ é diagonal (Anexo IV), existem no mínimo dois itens por variável latente e cada variável latente é padronizada (Anexo IV).

Com o primeiro passo do modelo identificável, passa-se para segunda etapa, na qual se examina o modelo como se ele fosse de equações estruturais para variáveis observadas. Neste caso, o modelo atende ao segundo passo, pois apresenta a matriz B nula (Anexo IV).

Sendo constatada a identificabilidade em todas as etapas, pode-se admitir que o modelo, como um todo, é identificável.

Assim, com a definição da identificabilidade do modelo, foi possível estimá-lo, o que significa encontrar os resultados no que se refere ao efeito das relações de interesse, de modo que a "distância" entre a matriz de variâncias e covariâncias estimada seja a menor possível em relação à matriz de variâncias e covariâncias populacionais (MARÔCO, 2010).

Por conseguinte, seguindo a análise do sistema, o método de estimação realizado foi o de máxima verossimilhança (ML), o qual se caracteriza por se basear nos resultados obtidos pela amostra, determinando qual a distribuição, entre todas aquelas definidas pelos possíveis valores de seus parâmetros, com maior possibilidade de ter gerado tal amostra, sendo o método mais utilizado para a estimação dos parâmetros, pois as estimativas do parâmetro de distribuição são mais precisas, a variância estimada é menor e os cálculos usam mais informações dos dados (BOLLEN, 1989; MARÔCO, 2010).

Em relação às formas de diagnóstico do ajustamento global do modelo, o primeiro índice de ajuste analisado foi o teste qui-quadrado de ajustamento. Este teste é conhecido pela sua rigidez, já que sua hipótese nula consiste na ideia de que a matriz de variância e covariância estimada é exatamente igual à populacional. Além disso, a sua utilização requer cuidados, pois é um teste altamente sensível ao tamanho da amostra. Neste teste, surgiram os seguintes resultados: 


\begin{tabular}{|c|c|}
\hline Método de Estimação & ML \\
\hline Valor da Função Mínima do Teste Estatístico & 69,293 \\
\hline Graus de Liberdade & 46 \\
\hline Pvalor do qui-quadrado & 0,015 \\
\hline
\end{tabular}

Tabela 1. Resultados do teste qui-quadrado de ajustamento. Fonte: Console do software R.

O Pvalor resultou em 0,015, ou seja, a hipótese nula de que a matriz de variância e covariância estimada é igual a populacional foi rejeitada, considerando-se a significância de 0,05 .

Outra informação que serviu de apoio no exame de ajustamento do modelo foi a observação do modelo baseline. O modelo baseline considera que os coeficientes de regressão do modelo estrutural são nulos e as cargas fatoriais do modelo de mensuração são unitárias, o que significa que não há nenhuma relação/influência entre as variáveis do modelo. Com este cenário, o baseline possui os seguintes valores:

\begin{tabular}{|c|c|}
\hline Valor da Função Mínima do Teste Estatístico & 1002,461 \\
\hline Graus de Liberdade & 66 \\
\hline Pvalor & 0,000 \\
\hline
\end{tabular}

Tabela 2. Resultados do modelo baseline. Fonte: Console do software R.

Portanto, comparando o qui-quadrado do primeiro teste (valor da função mínima do teste estatístico igual a 69,293) com o qui-quadrado do baseline (valor da função mínima do teste estatístico igual a 1022,461), infere-se que, no modelo proposto por este trabalho, há indícios de relação entre os mecanismos de governança de TI e a sua efetividade.

Existem tipos de testes menos rígidos e mais realistas, como o Índice de Ajuste Comparativo (CFI) e o Índice de Tuker-Lewis (TLI), os quais verificam a aceitabilidade da condição de superidentificação do modelo.

O CFI é a razão entre o ajustamento do modelo em estudo e o ajustamento do pior modelo possível (modelo baseline). Já o TLI foi proposto por Tuker e Lewis (1973) e por Bentler e Bonett (1980) e se diferencia do CFI pelo fato de incluir ajustes para modelos 
complexos, além de ser independente do tamanho amostral. Em ambos, os valores acima de 0,90 indicam bom ajuste do modelo e acima de 0,95 apontam que o ajustamento está muito bom (Bentler; Bonett, 1980; Klem; Yamould, 1995; Thompson, 2004).

Os resultados do sistema apontam que o ajustamento do modelo é muito bom, tanto para o CFI $(0,975)$ quanto para o TLI $(0,964)$.

Por fim, existe o Teste da Raiz do Erro Quadrático Médio de Aproximação (RMSEA), que é considerado um dos melhores critérios informativos para ser utilizado em modelagem de equações estruturais (Bollen, 1989). O RMSEA reflete a diferença média entre a covariância observada e a do modelo, sendo o erro do modelo de 0,061 , o que reflete um bom ajustamento do sistema (Hair et al., 1998; Thompson, 2004).

Além do mais, o Pvalor para o RMSEA menor ou igual a 0,05 para o modelo é de 0,259, o que reforça as evidências estatísticas de que o erro médio do modelo é mínimo, a tal ponto que se pode considerar que existe uma pequena distância entre as matrizes de variância e covariância estimadas e as de cunho populacional. A seguir, são apresentados os resultados do RMSEA:

\begin{tabular}{|c|c|}
\hline RMSEA & 0,061 \\
\hline Pvalor & 0,259 \\
\hline
\end{tabular}

Tabela 3. Resultados do teste RMSEA. Fonte: Console do software R.

Assim, analisando-se os vários testes, constata-se que apenas o teste qui-quadrado de ajustamento depõe contra a construção teórica formulada, tendo em vista que a maioria dos outros exames ratificaram a boa ajustabilidade do sistema.

Com as considerações feitas sobre o modelo, passa-se à apresentação dos resultados referentes ao teste de hipóteses. 


\subsection{RESULTADO DOS TESTES DE HIPÓTESES}

Para testar as hipóteses da dissertação, averiguou-se três questões: a relação entre as variáveis manifestas (itens do questionário) e suas respectivas variáveis latentes; a relação entre os mecanismos de governança de TI e a efetividade da governança (teste de hipóteses de forma estrita); e as variâncias e covariâncias. De antemão, avisa-se que o significado das siglas utilizadas na programação estão discriminadas em anexo próprio (Anexo IV).

Nas primeira e segunda questões, conforme se observa na figura abaixo, todas as relações propostas são significativas (possuem significância menor ou igual 0,05), sendo excluídas da análise as variáveis marcadas. As exceções quanto à significância estão nas seguintes associações: na relação entre o suporte da alta administração (SADM) e a efetividade da governança de TI (EGTI), cujo Pvalor é igual a 0,166; na influência da utilização do planejamento estratégico de TI (UPETI), na efetividade da governança de TI (EGTI), cujo Pvalor resultou em 0,150; e na relação entre a atuação do comitê de TI (ACDTI) e a efetividade da governança de TI (EGTI), cujo Pvalor é igual a 0,980. 


\begin{tabular}{|c|c|c|}
\hline \multicolumn{3}{|c|}{ Relação entre as variáveis latentes e manifestas } \\
\hline & Valor Estimado & $\mathbf{P}(>|\mathbf{z}|)$ \\
\hline \multicolumn{3}{|l|}{ SADM = } \\
\hline V8 & 1,000 & \\
\hline V9 & 0,923 & 0,000 \\
\hline V10 & 1,042 & 0,000 \\
\hline \multicolumn{3}{|c|}{ UPETI = } \\
\hline V11 & 1,000 & \\
\hline V12 & 1,075 & 0,000 \\
\hline V13 & 1,039 & 0,000 \\
\hline \multicolumn{3}{|l|}{ ACDTI $=\sim$} \\
\hline V14 & 1,000 & \\
\hline V15 & 1,672 & 0,002 \\
\hline \multicolumn{3}{|c|}{ AGPITI = } \\
\hline V16 & 1,000 & \\
\hline V17 & 0,929 & \\
\hline \multicolumn{3}{|l|}{ EGTI = } \\
\hline V18 & 1,000 & \\
\hline V19 & 1,048 & 0,000 \\
\hline \multicolumn{3}{|c|}{ Regressão } \\
\hline & Valor Estimado & $\mathbf{P}(>|\mathbf{z}|)$ \\
\hline \multicolumn{3}{|l|}{ EGTI } \\
\hline SADM & 0,304 & 0,166 \\
\hline UPETI & 0,222 & 0,150 \\
\hline ACDTI & $-0,031$ & 0,980 \\
\hline AGPITI & 0,393 & 0,016 \\
\hline \multicolumn{3}{|l|}{ AGPITI } \\
\hline ACDTI & 0,256 & 0,001 \\
\hline
\end{tabular}

Tabela 4. Resultados da relação entre as variáveis do modelo. Fonte: Console do software R.

A atuação do comitê de TI (ACDTI) sobre a gestão de portfólio de investimentos de TI (AGPITI) é significativa, ou seja, com Pvalor igual a 0,001, considerando-se que a significância também ocorre quando se verifica a influência da atuação da gestão de portfólio de investimentos de TI (AGPITI) sobre a efetividade da governança de TI (EGTI), já que seu Pvalor é igual a 0,016. 
Assim, conclui-se que a relação observada entre a variável independente - atuação do comitê de TI (ACDTI) - e a variável dependente - efetividade da governança de TI (EGTI) é mais eficaz quando esta ligação ocorre por meio da variável mediadora - atuação da gestão de portfólio de investimentos de TI (AGPITI) - do que quando há uma influência direta do comitê (ACDTI) sobre a efetividade da governança (EGTI).

O entendimento se fortalece quando se verifica o coeficiente de regressão negativo da relação entre a atuação do comitê de TI (ACDTI) e a efetividade da governança de TI (EGTI) (valor estimado $=-0,0301)$ em contraposição ao coeficiente positivo oriundo da multiplicação dos coeficientes de regressão da influência do comitê (ACDTI) sobre a gestão de portfólio de investimentos (AGPITI) e da influência da gestão de portfólio de investimentos (AGPITI) sobre a efetividade da governança de TI (EGTI) (valor estimado dos efeitos totais $=0,256 * 0,393=0,101)$.

Continuando a análise, novamente percebe-se o papel não considerável da atuação direta do comitê de TI (ACDTI) sobre a efetividade da governança de TI (EGTI) quando se analisa as variâncias dos componentes do sistema. No caso, este mecanismo possui a variância não significativa (Pvalor $=0,084)$, como se verifica no resultado abaixo. 


\begin{tabular}{|c|c|c|}
\hline & $\begin{array}{c}\text { Variâncias } \\
\text { Valor } \\
\text { Estimado }\end{array}$ & $\mathbf{P}(>|\mathbf{z}|)$ \\
\hline EGTI & 0,150 & 0,001 \\
\hline SADM & 1,020 & 0,000 \\
\hline UPETI & 1,111 & 0,000 \\
\hline ACDTI & 0,097 & $\mathbf{0 , 0 8 4}$ \\
\hline AGPITI & 0,394 & 0,002 \\
\hline V8 & 0,453 & 0,000 \\
\hline V9 & 0,677 & 0,000 \\
\hline V10 & 0,254 & 0,000 \\
\hline V11 & 0,616 & 0,000 \\
\hline V12 & 0,289 & 0,000 \\
\hline V13 & 0,255 & 0,000 \\
\hline V14 & 0,826 & 0,000 \\
\hline V15 & 0,743 & 0,000 \\
\hline V16 & 0,523 & 0,000 \\
\hline V17 & 0,430 & 0,000 \\
\hline V18 & 0,307 & 0,000 \\
\hline V19 & 0,249 & 0,000 \\
\hline & & \\
\hline
\end{tabular}

Tabela 5. Resultados das variâncias. Fonte: Console do software R.

Portanto, entre as hipóteses formuladas, foram observadas as evidências estatísticas de que:

H1: O suporte da alta administração não tem influência direta e positiva na efetividade da governança de TI.

H2: A atuação do comitê de TI não tem influência direta e positiva na efetividade da governança de TI.

H3: O efeito total (efeitos diretos e indiretos) da atuação do comitê de TI tem influência direta e positiva na efetividade da governança de TI. 
H4: A atuação do comitê de TI tem influência direta e positiva na atuação da gestão de portfólio de investimentos de TI.

H5: A atuação da gestão de portfólio de investimentos de TI tem influência direta e positiva na efetividade da governança de TI.

H6: A utilização do planejamento estratégico de TI não tem influência direta e positiva na efetividade da governança de TI.

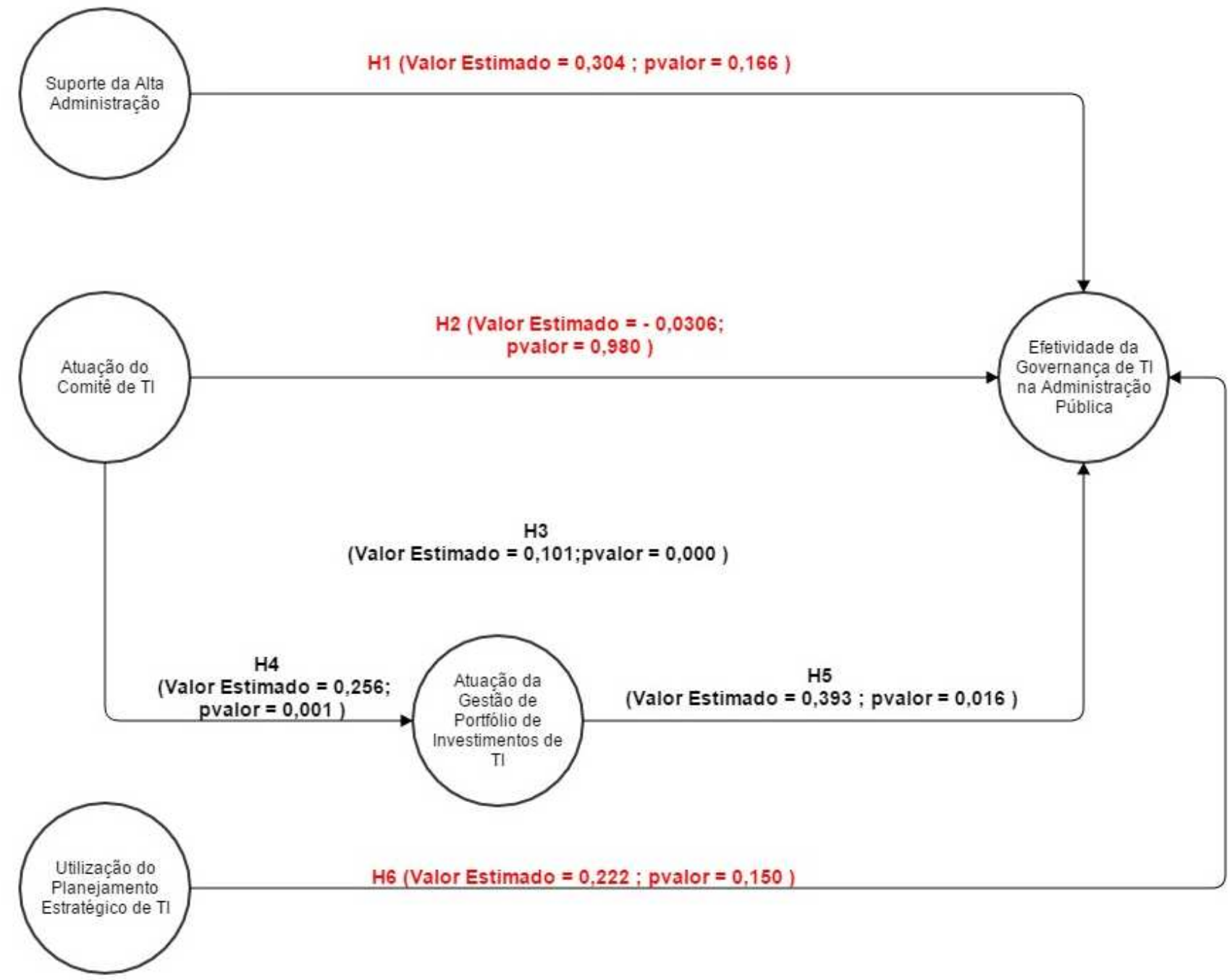

Figura 5. Modelo estrutural com os valores estimados e as significâncias das hipóteses. Fonte: Console do software R. 


\section{DISCUSSÃO E CONSIDERAÇÕES FINAIS}

O capítulo de discussão e considerações finais está organizado da seguinte forma: primeiro serão analisados os resultados da pesquisa com as suas interpretações; em seguida, serão apresentadas as limitações da pesquisa com as sugestões de trabalhos futuros.

\subsection{ANÁLISE E INTERPRETAÇÃO DOS RESULTADOS DA PESQUISA}

Este trabalho buscou atender o propósito de realizar um estudo de identificar e entender o atendimento dos objetivos definidos pelas estratégias da organização para governança de TI por meio das relações entre os mecanismos de governança de TI e a efetividade desta. A partir desta meta base, formulou-se e testou-se as hipóteses com seus respectivos resultados elencados no capítulo anterior.

Neste subcapítulo, serão abordadas as análises e as interpretações dos efeitos e dos seguimentos observados.

No que tange ao mecanismo denominado suporte da alta administração, verifica-se que a literatura aponta a sua essencialidade e a sua influência na estratégia e na efetividade organizacional, sendo a alta administração o ente que determina o uso, o desenvolvimento e o desdobramento dos recursos organizacionais (Hambrick; Mason, 1984; Rajagopalan; Rasheed; Datta, 1993; Papadakis; Barwise, 2002; Serra, Ferreira; Fiates, 2007).

Todavia, no que se refere à relação entre a alta administração e a governança de TI, ressalta-se que o suporte da alta administração consiste em um mecanismo de relacionamento complexo, pois a sua presença deve se manifestar por meio do envolvimento de práticas e arranjos organizacionais, além da atuação transversal às estruturas e aos processos.

Isto significa que este mecanismo possui uma dificuldade de implantação, já que a alta administração precisa desencadear outras ações/mecanismos para estar mais presente no dia a dia das organizações, fazendo valer, de fato, o seu apoio à governança de TI. 
Esta complexidade se avoluma quando se analisa a alta administração do setor público, pois, além de ser marcada pela rotatividade e pela concretização dos objetivos sociais que justificam a sua permanência no órgão, ela também é permanentemente influenciada e dirigida pelos valores e sistemas políticos, por maiores constrangimentos legais e formais, e por maior dificuldade em criar incentivos para requerer performances mais efetivas e eficientes (Almeida; Cruz, 2002).

Cumpre destacar que significativa parte da alta burocracia federal é estabelecida mediante à lógica do presidencialismo de coalizão, no qual o presidente, para conseguir maioria no Congresso Nacional, distribui certo número de cargos na burocracia entre os partidos aliados (Praça; Freitas; Hoepers, 2011).

Esta lógica é capaz de promover a perda da experiência organizacional e temática de burocratas especialistas que possuem funções de policymaking, dificulta a implementação da avaliação da efetividade do serviço público, além de desperdiçar a experiência dos burocratas com redes informais de poder em áreas específicas como a de tecnologia da informação (Abrucio, 1993; Carpenter, 2001; Lewis, 2008). Em resumo, a alternância pode afetar a estabilidade do apoio da alta burocracia às políticas de governança tecnológica pública.

Diante da transitoriedade, da ambiguidade de políticas, dos objetivos e dos amplos grupos de interesse, fica claro que a questão da governança tecnológica é apenas mais um item da agenda da alta gerência e, quando ocorre o suporte "oficial" da alta administração, este não se reverte ou se transforma pouco em medidas concretas e contínuas.

Assim, interpreta-se do resultado da pesquisa que, se existe a ausência de ações concretas ou se estas medidas oriundas da alta administração estatal não perduram, consequentemente a percepção dos servidores sobre o papel do suporte da alta burocracia na efetividade da governança é reduzida. Esta percepção é corroborada por pesquisas que indicam a presença de uma falta de confiança por parte dos servidores públicos em relação à 
sua alta administração e à capacidade que esta tem de estabelecer uma visão clara e permanente do futuro estratégico das instituições públicas. (Morehead et al, 1997; Davis; Landa, 1999; Albrecht; Travaglione, 2003; Young; Daniel, 2003; Coats, 2005; Massey; Pyper, 2005; Mayer; Gavin, 2005).

Esta conjuntura revela como a administração pública contemporânea brasileira não está plenamente inserida nos modelos da Nova Gestão Pública/Nova Governança Pública, apresentando uma mistura de características oriundas do patrimonialismo e do modelo burocrático weberiano.

A Nova Gestão Pública e a Nova Governança Pública idealizam uma alta administração calcada na competência técnica e meritocrática, sendo indutora da modernização por meio do uso de tecnologias de informação e apoiadora de programas de governo que utilizem a tecnologia como forma de promover desempenho, eficiência, eficácia, transparência e qualidade nas relações com os cidadãos e demais stakeholders (Osborne, 1997; Behn, 1998; Bresser-Pereira, 2002; Ronaghan, 2002; Medeiros, 2004; Prado, 2004; Agune; Carlos, 2005; Grant; Chau, 2005; Tan; Pan Shan, 2005).

Entretanto, conforme abordado anteriormente, não é este o cenário público federal brasileiro, o qual é caracterizado pela inexperiência das elites sociais e políticas em relação às experiências democráticas de reformismo calcado no debate, na negociação e num processo decisório menos concentrados, o que leva ao empecilho na implementação plena da reforma da gestão pública (Abrucio, 2010).

Sobre a atuação do comitê de TI, destaca-se que ele é um mecanismo de estrutura, logo está envolvido com a composição organizacional para que a governança de TI funcione, o que implica na necessidade de arranjos. Estes arranjos são constituídos de maneira diversa entre as organizações públicas e privadas. 
No setor privado, há uma definição clara sobre os papéis e as responsabilidades do comitê, pois estes são constituídos com o objetivo central de monitorar e dirigir a tecnologia da informação empresarial. Com esta meta definida, os seus executivos consequentemente também exercem suas funções de forma delimitada e fixada dentro do grupo com o fim de dar retorno (lucro) à instituição. Esta forma de funcionamento explica a influência positiva da atuação do comitê de TI detectada em estudos anteriores no ambiente privado (Karimi, 2000; Vaswani, 2003; Ali; Green, 2005).

No setor público, isto não fica claro, pois existem vários níveis de responsabilidade (e de interesses) dentro e fora das organizações, inclusive em âmbitos local, estadual e federal, o que aumenta as tensões e os conflitos na realização de negócios.

Este cenário do ambiente público conduz as seguintes ocorrências: ambiguidade nos papéis e nas responsabilidades dos principais intervenientes no processo de tomada de decisão; conflito de interesses, especialmente conflito de papéis; limites à independência do conselho; e processos de nomeação deficientes (Edwards; Clough, 2005), o que justifica o resultado da pesquisa.

Diante deste quadro, o trabalho identificou que, somente com a mediação da gestão de portfólio de investimentos de TI, se tornam estatisticamente significativos os efeitos percebidos de melhorias de desempenho em comitê de TI sobre a efetividade. Todavia, a utilização da mediação não significa que há debilidade nos efeitos observados, apenas indicando que eles interagem de forma mais complexa.

Esta interação da mediação e da relação significativa entre o comitê de TI e a gestão de portfólio se mostra importante e impactante para o modelo como um todo, provavelmente porque ao tratar do mecanismo de atuação na gestão de portfólio de investimentos de TI, está se trabalhando com um critério ligado à área econômico-financeira. 
Segundo a literatura sobre efetividade das organizações, a questão econômicofinanceira (controle de custos, orçamentos e retorno sobre os investimentos em TI) é um dos principais critérios para monitorar a efetividade organizacional, tendo em vista que isto se fortalece no caso da tecnologia da informação no setor público.

Este destaque acontece porque a tecnologia pública ainda apresenta um caráter funcional (Aguilera; Jackson, 2011), além de haver uma forte dependência de autorizações orçamentárias vinculadas a processos legais dentro do contexto público, problemas de escassez e contingenciamento de recursos (Ring; Perry, 1985).

Portanto, as questões orçamentárias podem ter um impacto significativo sobre o processo de formulação de políticas de governança de TI no setor público. Afinal, o processo orçamentário é a arena em que se determina a alocação dos recursos escassos da sociedade e, como tal, é um elemento fundamental do processo de formulação de políticas. Mesmo que estas já tenham recebido aprovação em outras esferas, elas precisam passar pelo orçamento para garantir que haja disponibilidade dos recursos necessários para implementá-las com efetividade (BID, 2007).

Desta forma, observa-se a importância da atuação da gestão de investimentos de portfólio de TI, já que ele objetiva a priorização dos projetos e de seus investimentos, decidindo como dividir os escassos recursos entre eles e levando em consideração as limitações de recursos e as necessidades do negócio, alinhando-os com os objetivos estratégicos organizacionais e considerando o alto grau de incerteza associado à utilização de tecnologias (Cooper; Edgett; Kleinschmidt, 2001; Irani; Love, 2002; Kerzner, 2002).

Portanto, o comitê de TI, por si só, não impacta a efetividade, apenas atingindo este objetivo quando recebe a incumbência de dirigir o alinhamento das ações e dos investimentos de TI, ou seja, quando recebe a missão de reger um mecanismo da importância e do peso que é a gestão de portfólio de investimentos de tecnologia da informação. Reitera-se que sua 
importância e seu peso ocorrem porque ele é um componente econômico-financeiro que promove a maximização de valor, o balanceamento e o alinhamento estratégico dos investimentos, justificando os investimentos em tecnologia frente a uma rígida estrutura orçamentária (Kumar; Ajja; Niu, 2008).

Em relação à utilização do planejamento estratégico de $\mathrm{TI}$, detecta-se a não significância da utilização do planejamento estratégico sobre a efetividade de governança pode ser ocasionada por problemas na implementação e na definição dos métodos e processos, os quais são condições necessárias para o sucesso do planejamento estratégico de TI (Synott; Gruber, 1982; Lederer; Mendelow, 1987; Lederer; Sethi, 1988). Estes problemas podem ter origem nas mesmas características do setor público que impactam na não influência do suporte da alta administração e na atuação do comitê de TI sobre a efetividade da governança de tecnologia da informação.

\subsection{LIMITAÇÕES DA PESQUISA E SUGESTÃO DE TRABALHOS FUTUROS}

A realização deste trabalho apresentou restrições quanto ao tamanho da amostra, o qual é restrito diante da quantidade de organizações públicas federais brasileiras que são do tipo núcleo estratégico e atividades exclusivas.

Também existem limitações quanto à escala escolhida, pois questiona-se a permanência do item "Não sabe/ Não responde" para um grupo de respondentes que são experientes no tema governança de TI.

Todavia, como aspecto positivo a ser destacado, este trabalho utilizou a opinião dos pesquisados para avaliar a importância dos itens do questionário e da sua medida.

Em relação à sugestão de pesquisas futuras, ressalta-se que o trabalho utilizou a técnica de análise de mediação do mecanismo de atuação da gestão de portfólio de investimentos de TI na relação entre a atuação do comitê de TI e a efetividade da governança 
de TI. Assim, sugere-se a ampliação desta análise de mediação entre outros mecanismos de governança de TI, além da inclusão de análises de moderação entre os mecanismos.

Sobre a escala likert adotada neste trabalho, propõe-se a construção de estudos que utilizem categorias classificatórias voltadas para pesquisados que entendam do assunto, ou seja, escalas que não admitam ausências de respostas, haja vista que os respondentes têm capacidade e experiência técnica para manifestar um posicionamento sobre a matéria.

Outra proposta elencada é de um estudo sobre a adesão de mecanismos de governança de TI não operacionais por meio de um aspecto institucional e os efeitos do isomorfismo/mimetismo na percepção da efetividade da governança de TI, já que estes fenômenos são relevantes no processo de interação entre os mecanismos e a efetividade.

Também se vislumbra a necessidade de estudos sobre a efetividade da governança de TI e os seus mecanismos em instituições governamentais que trabalham com serviços não exclusivos e na produção de bens e serviços para o mercado, além de ampliar as pesquisas para os âmbitos estadual e municipal.

Por fim, sugere-se, como pesquisa futura, a própria replicação deste estudo com fins de validação de seus resultados e saneamento das limitações que esta pesquisa teve como descrição anterior. 


\section{REFERÊNCIAS}

ABBASI, M. R.; SHAHAMATI, M. Designing of Knowledge Management Critical factors Strategic Matrix in Banking Industry (Case Study: Eghtesade Novin Branches of Iran). Institute of Interdisciplinary Business Research, 2 (11), 530-544, 2011.

ABNT. ABNT NBR ISO/IEC 38500/2009 - Governança corporativa de tecnologia da informação,2009. Disponível em:〈http://www.abntcatalogo.com.br/norma.aspx? ID=40015>.

ABRUCIO, F. L."Profissionalização". In: Andrade, Regis de Castro e Jaccoud, Luciana (orgs.). Estrutura e organização do Poder Executivo: administração pública brasileira. Brasília: enap/cedec, pp.33-107, 1993.

ABRUCIO, F. L. Reforma da gestão pública nos estados: avanços e desafios na institucionalização de uma agenda. In: CONSAD. Avanços e perspectivas da gestão pública nos estados II. Brasília: CONSAD, 2010.

AGUILERA, R. V. e; JACKSON, G. Comparative and International Corporate Governance. Rochester: n/a p. 2011.

AGUNE, R.; CARLOS, J. Governo eletrônico e novos processos de trabalho. In: LEVY, E.; DRAGO, P. (Orgs.). Gestão pública no Brasil contemporâneo. São Paulo: Fundap, 2005.

ALBRECHT, S.; TRAVAGLIONE, A. "Trust in public-sector senior management", International Journal of Human Resource Management, Vol. 14 No. 1, pp. 76-92, 1997.

ALFORD, J. Defining the client in the public sector: A social exchange perspective. Public Administration Review, 62, 337-346, 2002.

ALI, S.; GREEN, P. Determinants of effective information technology governance: A study of IT intensity. Proceedings of IT Governance International Conference. Auckland, New Zealand, pp. 15- 26, 2005.

ALI, S.; GREEN, P. IT Governance mechanisms in public sector organizations: An Australian context. Journal of Global Information Management, 15, 4, 41-63, 2007.

ALMEIDA, M. I. R. de; CRUZ, J. M. F. Planejamento estratégico para instituições governamentais. Anais do XV Congresso Latino-Americano de Estratégia (SLADE), Montevidéu, 2002.

AMMONS, D. N., RIVENBARK, W. C. Factors influencing the use of performance data to improve municipal services: Evidence from the North Carolina benchmarking project. Public Administration Review, 68, 304-318, 2008. 
ANDREWS, R.; BOYNE, G. A.; LAW, J.; WALKER, R. M. Centralization, Organizational Strategy and Public Service Performance. Journal of Public Administration Research and Theory, 19 (1), 57-80, 2009.

ARCHER, N. P.; GHASEMZADEH, F. An integrated framework for project portfolio selection. International Journal of Project Management, v. 17, n. 4, p. 207-216, 1999.

ARMSTRONG C.P., SAMBAMURTHY V. Information technology assimilation in firms: the influence of senior leadership and IT infrastructures. Information System Research; 10(4) p. 304-31. 1999.

BARRETT, P. Corporate Governance and Accountability for Performance. In: Seminar by IPAA and ASCPAs. Canberra, 1997.

BARRETT, P. Achieving Better Practice Corporate Governance in the Public Sector. AM Auditor General for Australia. Canberra, 2003.

BEAL, A. Gestão Estratégica da Informação. São Paulo: Atlas, 2004.

BEHN, R. D. O novo paradigma da gestão pública e a busca da accountability democrática. Revista do Serviço Público, Brasília, DF, ano 49, n. 4, out./dez. 1998.

BENTLER, P. M.; BONETT, D. G. Significance test and goodness of fit in the analysis of covariance structures. Psychological Bulletin, v. 88, n 1, p. 588-606, 1980.

BERNARD, P. COBIT 5 - A management guide, Van Haren Publishing, 2012.

BID Banco Interamericano de Desenvolvimento. A Política das Políticas Públicas: relatório de progresso econômico e social na América Latina. Rio de Janeiro: Elsevier, 2007.

BOLLEN, K. A. Structural equations with latent variables. John Wiley \& Sons, New York, 1989.

BOVAIRD, T. 'Beyond Engagement and Participation: User and Community Coproduction of Public Services’, Public Administration Review, Vol. 67, pp. 846-60, 2007.

BOWEN, Paul L.; CHEUNG, May-Yin D.; ROHDE, Fiona H. Enhancing IT governance practices: A model and case study of an organization's efforts. International Journal of Accounting Information Systems, v. 8, n. 3, p. 191-221, set. 2007.

BRANCHEAU, J.; WETHERBE, J. C. Key issues in information systems - 1986. MIS Quarterly, Vol. 11, No 1, pp. 23-46, 1987.

BRASIL, Presidente. Plano Diretor da Reforma do Aparelho do Estado. Brasília: Presidência da República, Câmara da Reforma do Estado, Ministério da Administração Federal e Reforma do Estado, 1995.

BRASIL. Decreto-lei n 5.378 de 23 de fevereiro de 2005. Institui o Programa Nacional da Gestão Pública e Desburocratização - GESPÚBLICA. Diário Oficial da República Federativa do Brasil, Brasília, DF, 24 fev. 2005. p. 2. 
BRASIL, TCU. Levantamento de governança de TI 2010. $1^{\text {a }}$ Ed. Brasília: Tribunal de Contas da União, Relator Ministro Aroldo Cedraz. - Brasília: TCU, Secretaria de Fiscalização de TI, 2010.49p. Disponível em: <portal2.tcu.gov.br/portal/pls/portal/docs/2056484.PDF>.

BRESSER-PEREIRA, L. C. Reforma do Estado para a cidadania. A reforma gerencial brasileira na perspectiva internacional. Brasília: Enap/Editora 34, 1998.

BRESSER-PEREIRA, L. C. Reforma da nova gestão pública: agora na agenda da América Latina, no entanto. Revista do Serviço Público, ano 53, n. 1, jan./mar. 2002.

BRESSER-PEREIRA, L. C. The Structural Public Governance Model. International Public Management Review, v. 8, p. 16-32, 2007.

CAMERON, K. S. Effectiveness as Paradox: Consensus and Conflict in Conceptions of Organizational Effectiveness. Management Science, v. 32, n. 5, p. 539-553, 1986.

CARPENTER, Daniel P. The forging of bureaucratic autonomy: reputations, networks, and policy innovations in executive agencies, 1862-1928. Princeton: Princeton University Press, p. 29, 2001.

CASTRO, H. G. D.; CARVALHO, M. M. D. Gerenciamento do portfolio de projetos: um estudo exploratório. Gestão \& Produção, São Carlos, v. 17, n. 2, p. 283-296, 2010.

CAVAliERI, A.; MACEDO-SOARES, T. D. L. v. A. d.; THIOLLENT, M. Avaliando o desempenho da universidade. Rio de Janeiro: Editora PUC-Rio; São Paulo: Edições Loyola, 2004.

COOPER, R. G.; EDGETT, S. J.; KLEInSCHIMDT, E. J. Portfolio Management for New Products. 2nd Ed., NY: Perseus Publishing, 2001.

DAVENPORT, T. H. Process, Innovation, Reengineering Working through Information Technology. Harvard Business School Press, Boston, 1993.

DAVENPORT, T. H. Ecologia da Informação: por que só a tecnologia não basta para o sucesso na era da informação. São Paulo: Futura, 2001.

DAVIS, T.; LANDA, M.J. “The trust deficit”, Canadian Manager, Vol. 24 No. 1, pp. 10-27, 1999.

DECHOW, P.M.; GE, W.; LARSON, C. R.; SLOAN, R.G. Predicting material accounting misstatements. Contemporary Accounting Research, Vol 28., No 1, pp. 17-82, 2011.

DE HAES, S.; VAN GREMBERGEN, W. Information Technology Governance Best Practices in Belgian Organisations. Proceedings of the 39th International Conference on System Sciences. Hawaii, 2006.

DE HAES, S.; VAN GREMBERGEN, W. Analysing the Relationship between IT Governance and Business/IT Alignment Maturity. In: 41th Hawaii International Conference on System Sciences. IEEE Computer Society. 2008. 
DE HAES, S.; VAN GREMBERGEN, W. An Exploratory Study into IT Governance Implementations and its Impact on Business/IT Alignment. Information Systems Management 26(2):123-137, 2009.

DENHARDT, R.B., J.V. DENHARDT. 'The New Public Service: Serving Rather than Steering'. Public Administration Review, Vol. 60, No. 6, pp. 549-59, 2000.

DENHARDT, Robert B. Theories of Public Organization. 5th. ed. Belmont, CA: Thomson/Wadsworth, 2008.

DIMAGGIO, P.; POWELL, W. The Iron Cage Revisited: Institutional Isomorphism and Collective Rationality in Organizational Fields. In: American Sociological Review, Vol. 48, 1983.

DINIZ, E. H. et al. O Governo Eletrônico no Brasil: perspectiva histórica a partir de um modelo estruturado de análise. In: R.A.P., Rio de Janeiro, n. 43, v. 1, p. 23-48, jan./fev., 2009.

DIXON, P.J.; JOHN, D.A. Technology issues facing corporate management in the 1990's. MIS Quarterly, Vol. 13, No 3, pp. 247-255, 1989.

DOLL, W.J. Avenues for top management involvement in successful MIS department. MIS Quarterly, 9 (1), 17-35, 1985.

DOLL, W.J.; TORKZADEH, G. The relationship of MIS steering committees to size of firm and formalization of MIS planning. Communications of the ACM, Vol. 30, N 11 , pp. 972978, 1987.

DUNLEAVY, P., H. MARGETTS, S. BASTOW and J. TINKLE. 'New Public Management is Dead - Long Live Digital-Era Governance'. Journal of Public Administration Research and Theory, Vol. 16, No. 3, pp. 467-94, 2005.

DUNLEAVY, P.; MARGETTS, H. The Second Wave of Digital Era Governance. In: APSA 2010 ANNUAL MEETING PAPER. Paper. Washington, DC, 2010.

EARL, M.J. Management Strategies for Information Technology. Englewood Cliffs, NJ: Prentice-Hall, 1989.

EARL, M.J. Experiences in strategic information systems planning. MIS Quarterly (17:1) 1993, pp. 1-24.

EDWARDS, M.; CLOUGH, R. Corporate governance and performance: An exploration of the connection in a public sector context. Issue Series Paper $n^{\circ} 1$, Corporate Governance ARC Project. Universidade de Canberra, 2005.

EISENHARDT, K. Agency - and Institutional - Theory Explanations: The case of retail sales compensation. In: Academy of Management Journal, Volume 31, 1988.

EVERITT, S. Multivariate analysis: The need for data, and other problems. British Journal of Psychiatry. 126, 2S7-240, 1975. 
FERGUSON, C. et al. Determinants of effective information technology governance. International Journal of Auditing, v. 17, n. 1, p. 75-99, 2013. ISSN 10906738. Disponível em: 〈http://doi.wiley.com/10.1111/j.1099-1123.2012.00458.x 〉.

FERRAREZI, Elisabete e AMORIM, Sônia. Concurso inovação na gestão pública federal no Brasil: análise de uma trajetória. Cadernos ENAP. Brasília: ENAP, n 32, 2007.

FOTAKI, M. 'Towards Developing New Partnerships in Public Services: Users as Consumers, Citizens and/or Co-producers in Health and Social Care in England and Sweden'. Public Administration, Vol. 89, No. 3, pp. 933-55, 2011.

FREEMAN, R.E.; J. MCVEA. A Stakeholder Approach to Strategic Management, in M. Hitt, R.E. Freeman and J. Harrison (eds.), The Blackwell Handbook of Strategic Management (Oxford), pp. 189-207, 2001.

FREEMAN, R, E.; REED, D. L. Stockholders and Stakeholders: a new perspective on corporate governance. California Management Review, v. 25, n. 3, p. 88-106, 1983.

FROOMAN, J. Stakeholder influence strategies. Academy of Management Review, New York, Jstor, v. 24, n. 2, p. 191-203, 1999.

GAO. INFORMATION TECHNOLOGY INVESTMENT MANAGEMENT - A Framework for Assessing and Improving Process Maturity. Washington, D.C. (EUA): United States General Accounting Office, 2004.

GELINAS, U.; SUTTON, S.; FEDOROWICZ, J. Business Processes and Information Technology. Thompson Learning, Cincinnati, 2004.

GERALDO LOUREIRO, J.; SOUZA NETO, J. Diretrizes para Implantação da Governança de TI no Setor Público Brasileiro à Luz da teoria Institucional. Revista do Serviço Público, v. 64, p. 475-497, 2012.

GOODIN, R. E. (ed.) The Theory of Institutional Design. Cambridge, UK: Cambridge University Press, 1996.

GOODHUE D. L.; THOMPSON R. L. Task-technology fit and individual performance. MIS Quarterly, Vol. 19. (2): p.213-236. 1995.

GRANT, G.; CHAU, D. Developing a generic framework for e-government. Journal of Global Information Management, v. 13, n. 1, Jan./Mar. 2005.

GRANT, G.; MCKNIGHT, S.; URUTHIRAPATHY, A.; BROWN, A. Designing governance for shared services organizations in the public service. Government Information Quarterly, 24, 522-538, 2007.

GULDENTOPS, E.; VAN GREMBERGEN, W.; DE HAES, S. Control and governance maturity survey: establishing a reference benchmark and a self-assessment tool. Information Systems Control Journal, v6, p.32-35. 2004.

GUPTA, Y. P.; RAGHUNATHAN, T. S. Impact of information systems (IS) steering committees on IS planning, Decision Sciences, Vol. 20, No. 4, pp.777-93, 1989. 
HACKLER, D.; SAXTON, G. D. The Strategic use of information technology by Nonprofit Organizations: increasing capacity and untapped potencial. Public Administration Review, 67 (3), 474-487, 2007.

HAIR, Joseph F. Jr.; TATHAM, Ronald L.; ANDERSON, Ralph E.; BLACK, William C. Multivariate Data Analysis. New Jersey: Prentice Hall, 1998.

HAMBRICK, D.C. and MASON, P.A. Upper Echelons: The Organization as a Reflection of its Top Managers. Academy of Management Review. V. 9, p. 193-206, 1984.

HAMMER, M.; CHAMPY, J. A. Reengineering the Corporation: A Manifesto for Business Revolution. Harper Business Books, New York, 1993.

HATRY, H. P. Performance measurement: Fashions and fallacies. Public Performance \& Management Review, 25, 352-358, 2002.

HATRY, H. P. Looking into the crystal ball: Performance mover the next decade. Public Administration Review, 70, s208-s211, 2010.

HEINDRICKSON, G.; SANTOS Jr., C. D. d. Information Technology Governance in Public Organizations: How Perceived Effectiveness Relates to Three Classical Mechanisms. Revista de Gestão da Tecnologia e Sistemas de Informação (Online), v. 11, p. 2, 2014.

HENDERSON, J.; VENKATRAMAN, N. Strategic alignment: leveraging information technology for transforming organizations. IBM Systems Journal, v. 32, n.1, 1993.

HOOD, C. The new public management "e in the $1980^{\text {ee }}$ s: variations on a theme. Accounting, Organizations and Society, vol. 20. 2/3, p. 95 - 109, 1995.

HOLDEN, S. H. The Evolution of Federal Information Technology Management Literature. In: GARSON, D. (ed.). Modern public information technology systems: issues and challenges. Londres: IGI Global, 2007.

HUANG, R.; ZMUD, R. W.; PRICE, R. L. Influencing the effectiveness of IT governance practices through steering committees and communication policies. European Journal of Information Systems, v. 19, p. 288-302, 2010.

HUNTINGTON, S. A Ordem Política nas Sociedades em Mudança. São Paulo, Forense/Edusp, 1975.

IMASATO, T.; MARTINS, P. E. M.; PIERANTI, O. P. Administrative reforms and global managerialism: a critical analysis of three Brazilian state reforms. Canadian Journal of Administrative, 28(2), 174-187. doi: 10.1002/cjas.163, 2011.

International Federation of Accountants (IFAC), E-Business and the Accountant, New York: IFAC, 2002.

Information Systems Audit and Control Association (ISACA), IS Auditing Guideline, IT Governance Document Number 060.020.050, Rolling Meadows, IL: ISACA, 2002. 
Information Systems Audit and Control Association (ISACA), COBIT 5: Framework, Rolling Meadows, IL: ISACA, 2011.

IRANI, Zahir; LOVE, Peter E.D.A project management quality cost information system for the construction industry. Information \& Management, v.40, p.649-661, 2003.

ITGI, IT Governance Institute. Board Briefing on IT Governance, 2nd Edition. Illinois, USA, 2003.

ITGI, IT Governance Institute. Board briefing on IT Governance. 2nd ed. 2004.

ITGI, IT Governance Institute. About IT Governance Framework. ISACF, Information Systems Audit and Control Foundation. CobiT 4 Edition. Maio de 2007.

JACKSON, I.F. Corporate Information Management. Englewood Cliffs, NJ: Prentice-Hall, 1986.

JACOBSON, D. Revisting IT Governance in the Light of Institutional Theory. In: 42th Hawaii International Conference on Systems Science. IEEE Computer Society. 2009.

JAEGER NETO, J. I.; BECKER, C. A.; LUCIANO, E. M.; TESTA, M. G. A percepção dos gestores de TI em relação às práticas de Governança de TI adotadas em empresas do Rio Grande do Sul. RESI: Revista Eletrônica de Sistemas de Informação, v. 8, p. 5, 2009.

JARVENPAA, S. L.; IVES, B. Executive involvement and participation in the management of information technology. MIS Quarterly, Vol. 15, No 2, pp. 205-207, 1991.

KARIMI, J.; BHATTAACHERJEE, A.; GUPTA, Y.P.; SOMERS, T.M. The effects of MIS steering committees on information technology management sophistication. Journal of Management Information Systems, Vol. 17, № 2, pp. 207-230, 2000.

KERZNER, H. Gestão de projetos: as melhores práticas. Porto Alegre: Bookman, 2002.

KETTL, D. F. The global public management revolution: A report on the transformation of governance. Washington, DC: Brookings Institution, 2000.

KLEM, Laura; G. Grimm; Y ARNOULD, Paul R. Path Analysis: Reading and understanding Multivariate Statistics. Lawrence, ed. American Psychological Association, Washington, DC, 1995.

KORAC-KAKABADSE, N.; KAKABADSE, A. IS/IT governance: need for an integrated model. Corporate Governance, 1 (Num. 4), pp. 9-11, 2001.

KPMG, Fraud and Misconduct Survey 2010, Melbourne, Vic: KPMG International, 2010.

KRANACHER, M.; RILEY, R.A. Jr.; WELL, J. T. Forensic Accounting and Fraud Examination. New York: Wiley, 2010.

KUMAR, R., AJJAN, H. e NIU, Y. Information technology Portfolio Management: literature review, framework, and research issues. Information Resource Management Journal, v. 21, no 3, p. 64-87, 2008. 
LARSEN, G. L. Emerging governance at the edge of constrained federalism: Public administrators at the frontier of democracy (Dissertação de Doutorado). Portland State University, Portland, OR, 2008.

LEDERER, A. L.; MENDELOW, A. L. Information Resource Planning: Overcoming difficulties in identifying top management's objectives. MIS Quarterly, pp. 389-399, 1987.

LEDERER, A.L.; SETHI, V. The Implementation of Strategic Information Systems Planning Methodologies. MIS Quarterly, pp. 445-461, 1988.

LEWIS, David. The politics of presidential appointments: political control and bureaucratic performance. Princeton: Princeton University Press, p.58, 2008.

LIANG, T.; CHIU, Y.; WU, S. P.; STRAUB, D. The Impact of IT Governance on Organizational Performance. In: AMERICAS CONFERENCE ON INFORMATION SYSTEMS, Proceedings... Detroit: AMCIS. 2011.

LUFTMAN, J. N.; PAPP, R.; BRIER, T. Enablers inhibitors of business-IT alignment. Communications of AIS, Vol. 1, No. 11, pp. 1-33, 1999.

LUFTMAN, J. Assessing Business-IT Alignment Maturity. Communications of Association for Information Systems, v. 4, 2000.

LUNARDI, G. L. Um estudo empírico e analítico do impacto da governança de TI no desempenho organizacional. Tese (doutorado) - Universidade Federal do Rio Grande do Sul, Porto Alegre, 2008.

LUNARDI, G. L.; BECKER, J. L.; MAÇADA, A. C. G. Um estudo empírico do impacto da governança de TI no desempenho organizacional. Prod. [online], 2012.

MACDONALD, Ian. Making Strategy Operational. Bests. Rev. 105, n. 9, Janeiro, 2005.

MAHONEY J. Briefing for IT Leaders: Tomorrow's Trends and Today Decisions, Gartner Management Review, (46)2, p. 26-34.2012.

MALHORTA, N. K. Pesquisa de Marketing: uma orientação aplicada. Porto Alegre, Bookman, 2001.

MARÔCO, J. Análise de equações estruturais: Fundamentos teóricos, softwares e aplicações. Report number, Pêro Pinheiro, 2010.

MASSEY, A.; PYPER, R. Public Management and Modernisation in Britain, Palgrave Macmillan, London, 2005.

MATTAR, F. N. Pesquisa de marketing: metodologia e planejamento. 5. ed. São Paulo: Atlas, 1999.

MAYER, R.C.; GAVIN, M.B.“Trust in management and performance: who minds the shop while the employees watch the boss?", Academy of Management Journal, Vol. 48 No. 5, pp. 874-88., 2005. 
MCFARLAN, F. W. Portfolio approach to information systems. Harvard Business Review, v. 59, n. 5, p. 142-150, set-out 1981.

MCGEE, J.; PRUSAK, L. Gerenciamento Estratégico da Informação. Rio de Janeiro: Campus, 1994.

MCGUIRE, L. 'Service Charters - Global Convergence or National Divergence? A Comparison of Initiatives in Australia, the United Kingdom and the United States'. Public Management Review, Vol. 3, No. 4, pp. 493-524, 2001.

MCKEEN, J.D.; GUIMARÃES, T. Selecting MIS projects by steering committee. Communications of the ACM, vol. 28 (12), 1344-1352.

MCLEAN, E. R.; SODEN, J. V. Strategic Planning for MIS. New York, McGraw-Hill, 1977.

MEDEIROS, P. H. Governo eletrônico no Brasil: aspectos institucionais e reflexos na governança. Dissertação (Mestrado em Administração) - Universidade de Brasília (UnB), Brasília, 2004.

MELlO, G. R.; Governança Corporativa no Setor Público Federal Brasileiro. Dissertação de Mestrado em Ciências Contábeis. Universidade de São Paulo, 2006.

MERRIAM, S. B. Qualitive research and case study application in education. San Francisco: Jossey Bass, 2002.

MERRIEN F. X. De la gouvernance et des Etats-providence contemporains, Revue Internationale des Sciences Sociales, ${ }^{\circ}{ }^{155}$, pp. 61-71, 1998.

MEYER, J.; ROWAN, B.; Institutionalized Organizations: Formal Structure as Myth and Ceremony. In: The American Journal of Sociology, Vol 83.1977.

MILES, R. E.; SNOW, C. C. Organizational strategy, structure and process. New York: Mc Graw Hill, 1978.

MOORE, M. Public value as the focus of strategy. Australian Journal of Public Administration, 53, 296-303, 1994.

MOORE, M. Creating public value: Strategic management in government. Cambridge, MA: Harvard University Press, 1995.

MORAES, R. O.; LAURINDO, F. J. B. Um Estudo de Caso de Gestão de Portfolio de Projetos de Tecnologia Da Informação. G\&P Gestão \& Produção, v. 10, n. 3, p. 311-328, 2003.

MOREHEAD, A., STEELE, M., ALEXANDER, M., STEPHEN, K. and DUFFIN, L. Changes at Work: The 1995 Australian Workplace Industrial Relations Survey, Longman, Melbourne, 1997. 
MOYNIHAN, D. P., PANDEY, S. K. Testing how management matters in an era of government by performance management. Journal of Public Administration Research and Theory, 15, 421-439, 2005.

NFUKA, E. N.; RUSU, L. Critical Success Factors framework for implementing effective IT Governance in public sector organizations in a developing country. AMCIS 2011

Proceedings - All Submissions. Paper 365, 2011.

NIEDERMAN, F.; BRANCHEAU, J.C.; WETHERBE, J.C. Information systems management issues for the 1990's. MIS Quarterly, Vol. 15, No 4, pp.475-500, 1991.

NOLAN, R. L. Managing information systems by committee. Harvard Business Review, Vol. 60, pp. 72-99, 1982.

NUnNALLY, J. C. Psychometric Theory. New York, NY: McGraw-Hill, 1967.

O'FLYNN, J. From New Public Management to public value: Paradigm change and managerial implications. Australian Journal of Public Administration, 66, 353-356, 2007.

OSBORNE, D. Banishing bureaucracy: the five strategies for reinventing government. New York: Plume, 1997.

OSBORNE, S.P. 'The New Public Governance'. Public Management Review, Vol. 8, No. 3, pp. 377-87, 2006.

PAPADAKIS, V.M. \& BARWISE, P. How much do CEOs and Top Managers Matter in Strategic Decision-Making? British Journal of Management. V. 13, p. 83-95, 2002.

PARHIZGARI, A. M.; GILBERT, G. R. Measures of organizational effectiveness: private and public sector performance. Omega: The International Journal of Management Science, Vol. 32, No. 3, p. 221-229, 2004.

PETERSON, R. R., Configurations and coordination for global information technology governance: complex designs in a transnational European context. System Sciences, 2001.

PETERSON, R. R.; CALlAGHAN, R.; RIBBERS P. M. A. Information technology governance by design: investigating hybrid configurations and integration mechanisms. Proceedings of the 21 international conference on Information systems.pp.435-452. Brisbane, Queensland, Australia. 2000.

PETERSON, R. R. Information Strategies and Tatics for Information Technology Governance. In Van Grembergen (Ed.), Strategies for Information Technology Governance. Hershey, PA: Idea Group Publishing, 2003.

PFEFFER, J.; SALANCIK, G. The External Control of Organizations: A Resource Dependence Perspective. New York: Harper e Row, 1978.

POWELL, M., I. GREENER, I. SZMIGIN, S. DOHENY and N. MILLS. 'Broadening the Focus of Public Service Consumerism'. Public Management Review, Vol. 12, No. 3, pp. 323-39, 2010. 
PRAÇA, S.; FREITAS, A.; HOEPERS, B. Political appointments and coalition management in Brazil, 2007-2010. Journal of Politics in Latin America, v. 3, n. 2,p. 141-172, 2011.

PRADO, O. Governo eletrônico e transparência: a publicização das contas públicas das capitais brasileiras. 2004. 180 p. Dissertação (Mestrado em Administração de Empresas) Escola de Administração de Empresas de São Paulo da Fundação Getúlio Vargas, São Paulo, 2004.

PRASAD, A.; HEALES, J.; GREEN, P. A capabilities-based approach to obtaining a deeper understanding of information technology governance effectiveness: Evidence from IT steering committees. International Journal of Accounting Information Systems. v11, p.214-232, 2010.

RAJAGOPALAN, N.; RASHEED, A. M. A.; DATTA, D. K. Strategic decision processes: critical review and future directions. Journal of Management, 19(2), 349, 1993.

RAGHUNATHAN, B.; RAGHUNATHAN, T. S. MIS steering committees: their effect on information systems planning. Journal of Information Systems, Vol. 3, No. 2, pp. 104-16, 1989.

RAGHUNATHAN, B.; RAGHUNATHAN, T.S. Planning implications of the information systems strategic grid: an empirical investigation. Decision Sciences, Vol. 21, N 2, pp. 287300, 1990.

RING, P. S.; PERRY, J. L. Strategic management in public and private organizations: implications of distinctive contexts and constraints. The Academy of Management Review, v. 10, n. 2, p. 276-286, 1985.

ROCKART, J. F. Chief Executives Define Their Own Data Needs. Harvard Business Review, 81-92, 1979.

ROCKART, J. F.; SCOTT-MORTON, M. S. Implications of changes in information technology for corporate strategy. Interfaces, Vol. 14, No 1, pp. 28-31, 1984.

RONAGHAN, S. Benchmarking e-government: a global perspective. Assessing the progress of the UN member states. United Nations Division for Public Economics and Public Administration \& American Society for Public Administration, Maio, 2002.

SAMBAMURTHY, V.; ZMUD, R. W. Arrangements for information technology governance: A theory of multiple contingencies. MIS Quarterly, v. 23, n. 2, p. 261-290, Junho,1999.

SAMPIERI, R; COLLADO, C; LUCIO, P. Metodologia de Pesquisa. São Paulo: McGraw-Hill, 2006.

SECCHI, L. Modelos organizacionais e reformas da administração pública. Revista de Administração Pública, Rio de Janeiro, FGV, 43(2):347-69, mar.-abr., 2009.

SERRA, A.R.S; FERREIRA, M.P.; FIATES, G.G. Pilares da Estratégia: uma Proposta de Dimensões para Análise e Dimensionamento dos Recursos Estratégicos. Working paper séries Escola Superior de tecnologia e gestão do Instituto Politécnico de Leiria, 2007. 
SILVA, B. A. M., MORAES, G.H.S.M., Influência dos direcionadores do uso da TI na Governança de TI. Revista Brasileira de Gestão e Negócios, São Paulo, v13, n.38, p 41-60, 2011.

SIMMONS, R., J. BIRCHALL, S. DOHENY and M. POWELL. "“Citizen Governance": Opportunities for Inclusivity in Policy and Policy Making?', Policy and Politics, Vol. 35, No. 3, pp. 457-78, 2007.

SIQUEIRA, M. C. Gestão Estratégica da Informação: como transformar o conteúdo informacional em conhecimento valioso. Rio de Janeiro: Brasport, 2005.

STEINER, G.A. Strategic planning: What every manager must know. New York: Free Press, 1979.

STOKER, G. Public value management: A new narrative for networked governance? American Review of Public Administration, 36, 41-57, 2006.

SYNOTT, W.R.; GRUBER, W.H. Information Resource Management: Opportunities and Strategies for the 1980's. J. Wiley and Sons, New York, NY, 1982.

TAN, C.; PAN SHAN, L. Managing stakeholder interests in e-government implementation: lessons learned from a Singapore e-government project. Journal of Global Information Management, v. 13 p. 31, 2005.

THOMPSON, B. Exploratory and confirmatory factor analysis. Washington, DC: American Psychological Association, 2004.

TORRES, M. D. d. F. Estado, democracia e administração pública no Brasil. Rio de Janeiro: Editora FGV, 2004. 224 p.

VAN GREMBERGEN, W.; DE HAES, S.; GULDENTOPS, E. Structures, processes and relational mechanisms for IT governance. In: Strategies for Information Technology Governance. Win Van Grembergen editor. London, 2004.

VAN GREMBERGEN, W.; DE HAES, S. Enterprise Governance of Information Technology. New York: Springer, 2009.

VASWANI, R. Determinants of effective information technology (IT) governance. School of Business, University of Queensland, Australia, 2003.

WADE M.; HULLAND J. Review: the resource-based view and information systems research: review, extension, and suggestions for future research. MIS Quarterly. 28(1): p.107-42, 2004.

WARD, J. M. A Portfolio Approach to Evaluating Information Systems Investments and Setting Priorities. Journal of Information Technology, v. 5, p. 222-231, 1990.

WEILL, P.; ROSS, J.W. IT Governance: how top performers manage IT decision rights for superior results. Boston, Massachusetts, USA: Harvard Business School Press, 2004. 
WEILL, P.; ROSS, J. Governança de TI: Tecnologia da Informação. São Paulo: Makron Books, 2006.

WEILL, P.; WOERNER, S. L.; MCDONALD, M. Managing the IT Portfolio (Updated Circa 2009): Infrastructure Dwindling in the Downturn. MIT Center for Information Systems Research - Research Briefing, Cambridge-MA (EUA), v. IX, n. 8, ago. 2009.

WEILL, P.; WOERNER, S. L.; RUBIN, H. A. Managing the IT Portfolio (Updated Circa 2008): It's All About What's New. MIT Center for Information Systems Research Research Briefing, Cambridge-MA (EUA), v. VIII, n. 2B, jul. 2008.

WIEDENHÖFT, G. C. Identificação de critérios para monitorar a efetividade dos mecanismos de governança de tecnologia da informação. Porto Alegre, 2013. Dissertação (Mestrado) - Faculdade de Administração, Contabilidade e Economia, PUCRS.

WINKLER, T. J. IT Governance Mechanisms and Administration/IT Alignment in the Public Sector: A Conceptual Model and Case Validation. Wirtschaftsinformatik Proceedings 2013. Paper 53, 2013.

WHOLEY, J. S. (1999). Performance-based management: Responding to the challenges. Public Productivity \& Management Review, 22, 288-307, 1999.

WOODHEAD, B. After the sky fell in on atlas. The Australian Financial Review, 36, 2004.

YOUNG L.; DANIEL, K. (2003), “Affective trust in the workplace”, International Journal of Human Resource Management, Vol. 14 No. 1, pp. 139-55, 2003.

ZICKMUND, W. G. Exploring Marketing Research. Forth Worth. 6. ed. The Dryden Press, 1997. 


\section{Anexo I - Instrumento - Questionário}

1 - 0 participante da pesquisa trabalha em qual instituição pública? *

2 - Qual é o sexo do participante da pesquisa? *

Feminino

Masculino

3 - Qual é a idade do participante da pesquisa? *

De 18 a 29 anos

De 30 a 39 anos

De 40 a 49 anos

De 50 a 59 anos

60 anos ou mais

4 - Qual é o nível de escolaridade do participante da pesquisa? *

1 - Ensino Médio Completo

2 - Graduação

3 - Especialização de Nível Superior

4 - Mestrado

5 - Doutorado

5 - Qual a formação técnica e/ou acadêmica do participante da pesquisa? *

Tecnologia da Informação

Engenharia

Administração

Economia

Direito

Outra formação na área de Ciências Exatas

Outra formação na área de Ciências Humanas

Outro:

6 - Qual é o cargo/função atual do participante da pesquisa? *

Gestão/Governança de Tecnologia da Informação

Desenvolvimento de Sistemas

Infraestrutura/Suporte de Tecnologia da Informação

Controladoria/Auditoria

Orçamento e Finanças

Planejamento

Administração

Outro: 
7 - Há quantos anos completos o participante da pesquisa está na instituição na qual trabalha? *

(1) 1 a 3 anos

(1) 4 a 9 anos

(-) 10 a 15 anos

16 a 20 anos

20 a 25 anos

26 a 30 anos

(1) Mais de 30 anos

8 - A Alta Administração da instituição se responsabiliza pela avaliação e pelo estabelecimento das políticas de governança de TI? *

- Não sabe/Não responde

Discordo totalmente

- Discordo

Nem concordo nem discordo

Concordo

- Concordo totalmente

9 - A Alta Administração aprovou e publicou as diretrizes para gestão do portfólio de projetos e serviços de $\mathrm{Tl}$, inclusive para definição de critérios de sua priorização, inclusão, exclusão, manutenção e suprimento orçamentário? *

( ) Não sabe/Não responde

Discordo totalmente

- Discordo

Nem concordo nem discordo

Concordo

Concordo totalmente

10 - A Alta Administração avalia e monitora o cumprimento das políticas de governança de TI? *

Não sabe/Não responde

- Discordo totalmente

Discordo

Nem concordo nem discordo

- Concordo

Concordo totalmente

11 - A Alta Administração da organização aprovou o Planejamento Estratégico de TI? *

Não sabe/Não responde

Discordo totalmente

Discordo

- Nem concordo nem discordo

Concordo

Concordo totalmente 
12 - O Planejamento Estratégico de TI tem sido aplicado na organização? *

(1) Não sabe/Não responde

- Discordo totalmente

Discordo

- Nem concordo nem discordo

Concordo

Concordo totalmente

13 - A aplicação do Planejamento Estratégico de $\mathrm{Tl}$ tem apresentado resultados efetivos na organização? *

Não sabe/Não responde

- Discordo totalmente

- Discordo

- Nem concordo nem discordo

Concordo

Concordo totalmente

14 - Na organização existe um (ou mais de um) comitê de $\mathrm{Tl}$ ou estrutura equivalente, que conta com representantes das unidades de negócio e que atua na governança e gestão de $\mathrm{TI}$ da instituição? *

Não sabe/Não responde

Discordo totalmente

Discordo

Nem concordo nem discordo

Concordo

- Concordo totalmente

15 - 0 comitê de $\mathrm{Tl}$ acompanha/monitora a realização de benefícios, custos e riscos das soluçốes de TI mais importantes, na fase de projeto e na fase de operação e sustentação? *

Não sabe/Não responde

Discordo totalmente

- Discordo

- Nem concordo nem discordo

Concordo

Concordo totalmente

16 - A seleção e a priorização das propostas de novas soluções de TI baseiam-se em critérios claros, transparentes e previamente conhecidos por todos os envolvidos? *

Não sabe/Não responde

(1) Discordo totalmente

Discordo

- Nem concordo nem discordo

Concordo

Concordo totalmente 
17 - A seleção e a priorização das propostas de novas soluções de TI levam em consideração os benefícios estratégicos, financeiros, de melhoria de desempenho e informacionais possiveis de serem gerados por cada solução de TI para o negócio? *

Não sabe/Não responde

Discordo totalmente

Discordo

Nem concordo nem discordo

Concordo

Concordo totalmente

18 - A governança de TI da instituição facilita o alinhamento entre a Tl e os objetivos do negócio da instituição? *

Não sabe/Não responde

Discordo totalmente

Discordo

Nem concordo nem discordo

Concordo

Concordo totalmente

19 - A governança de Tl da instituição proporciona o atendimento das demandas e solicitações dos stakeholders da instituição com relação à área tecnológica? *
Não sabe/Não responde
Discordo totalmente
Discordo
Nem concordo nem discordo
Concordo
Concordo totalmente 


\section{Anexo II - Carta de Apresentação Eletrônica}

Prezada (respondente ou instituição),

Gostaria do apoio para aplicação de uma pesquisa acadêmica com funcionários que trabalham na (instituição) e que se envolvem e/ou entendem de governança de TI.

Esclarecendo melhor, esta pesquisa é parte integrante da dissertação do mestrando Leonel Cerqueira, sob a orientação do Prof. Dr. Carlos Denner dos Santos Júnior vinculado ao Programa de Pós-Graduação em Administração (PPGA) da Universidade de Brasília (UnB).

A pesquisa tem o objetivo acadêmico de identificar as relações dos mecanismos de governança de TI não operacionais influenciadores com a efetividade percebida da governança de TI em instituições públicas federais brasileiras. Os mecanismos a serem pesquisados são: Suporte da Alta Administração, Utilização do Planejamento Estratégico de TI, Atuação do Comitê de TI e Atuação da Gestão de Portfólio de investimentos.

Para esta pesquisa serão selecionados os gestores de tecnologia da informação, demais colaboradores das áreas de tecnologia da informação e profissionais experientes na área os quais trabalham em instituições públicas federais.

Será garantido o anonimato e confidencialidade dos dados pessoais dos participantes.

Não há respostas certas, pois o que importa é a opinião.

Informo que ao final da análise da pesquisa e defesa da dissertação, serão disponibilizados os resultados obtidos.

Espero o retorno e estou à disposição para maiores esclarecimentos.

Atenciosamente,

Leonel Cerqueira 


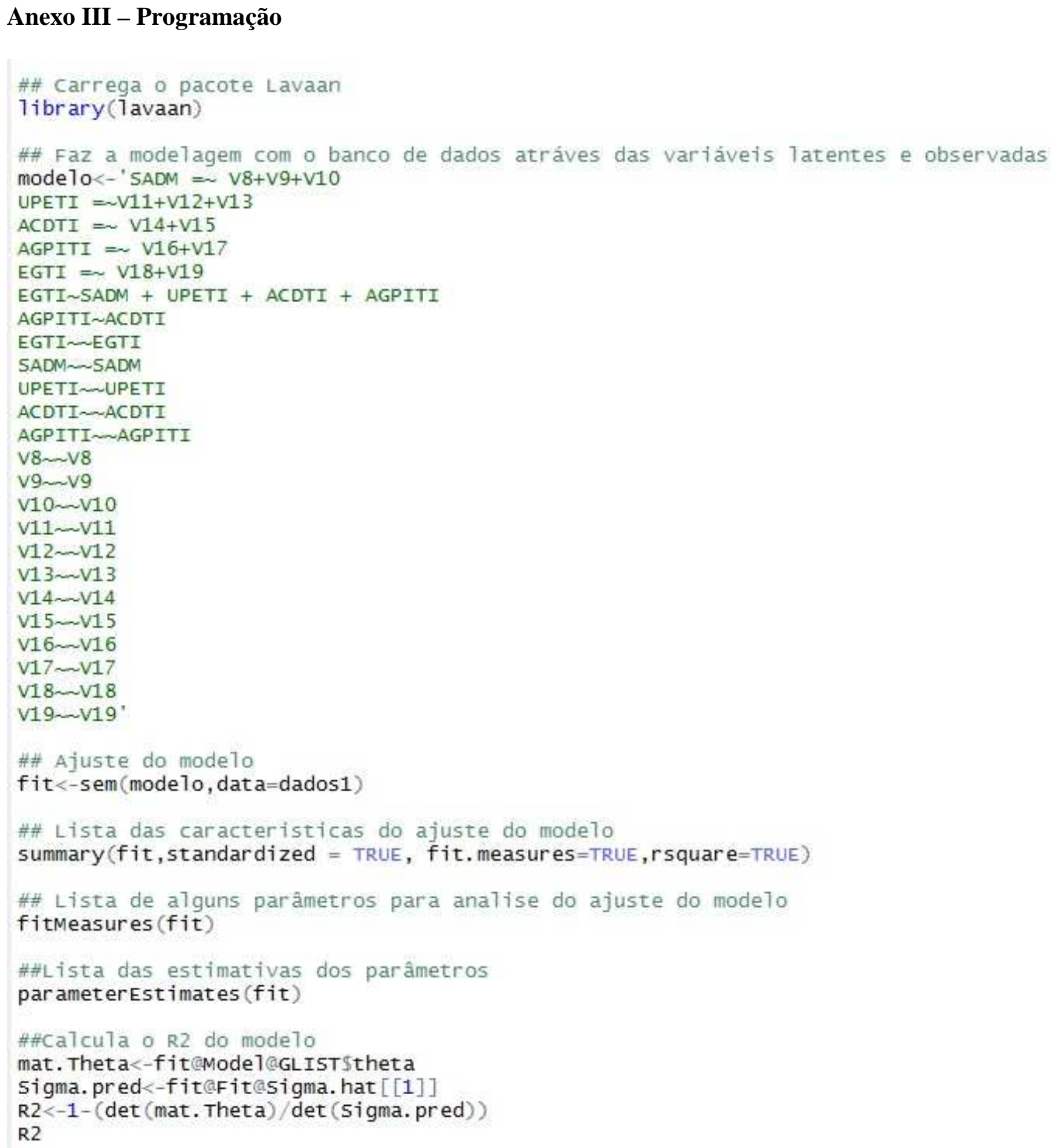




\section{Anexo IV - Construção dos grupos de equações matriciais com as suas matrizes de variâncias e covariâncias}

Qualquer modelo de equações estruturais pode ser escrito com base nos seguintes grupos de equações estruturais:

$\left\{\begin{array}{c}\eta=B \eta+\Gamma \varepsilon+\xi \\ y=\Lambda_{y} \eta+\varepsilon \\ x=\Lambda_{x} \varepsilon+\delta\end{array}\right.$

Porém, o modelo do trabalho se caracteriza pelo seguinte conjunto de equações com seus respectivos significados:

$\left\{\begin{array}{c}\eta=\Gamma \varepsilon+\zeta \\ x=\Lambda_{x} \varepsilon+\delta\end{array}\right.$

$\eta$ = variáveis latentes endógenas

$\Gamma=$ efeitos das variáveis latentes exógenas sobre outras latentes endógenas

$\varepsilon=$ variáveis latentes exógenas

$\xi=$ termo de erro para as variáveis latentes endógenas

$x=$ variáveis manifestas

$\Lambda_{x}=$ carga fatorial para variáveis exógenas

$\varepsilon=$ variáveis latentes exógenas

$\delta=$ termo de erro das variáveis manifestas

Além destes grupos de equações, ainda deve-se considerar o termo de erro para as exógenas $\left(\Theta_{\xi}\right)$, a matriz de covariância e variância para as latentes exógenas $(\phi)$ e a matriz de covariâncias (e termo de erro) para os erros das variáveis endógenas ( $\psi)$. Desta forma, as matrizes que indicam os parâmetros livres do modelo são: 


$\left[\begin{array}{c}V 8 \\ V 9 \\ V 10 \\ V 11 \\ V 12 \\ V 13 \\ V 14 \\ V 15 \\ V 16 \\ V 17 \\ V 18 \\ V 19\end{array}\right]=\left[\begin{array}{lllll}\lambda_{3} & 0 & 0 & 0 & 0 \\ \lambda_{9} & 0 & 0 & 0 & 0 \\ \lambda_{10} & 0 & 0 & 0 & 0 \\ 0 & \lambda_{11} & 0 & 0 & 0 \\ 0 & \lambda_{12} & 0 & 0 & 0 \\ 0 & \lambda_{13} & 0 & 0 & 0 \\ 0 & 0 & \lambda_{14} & 0 & 0 \\ 0 & 0 & \lambda_{15} & 0 & 0 \\ 0 & 0 & 0 & \lambda_{16} & 0 \\ 0 & 0 & 0 & \lambda_{17} & 0 \\ 0 & 0 & 0 & 0 & \lambda_{18} \\ 0 & 0 & 0 & 0 & \lambda_{19}\end{array}\right] *\left(\begin{array}{c}S A D M \\ U P E T I \\ A C D T I \\ A G P I T I \\ \delta_{9} \\ \delta_{10} \\ \delta_{11} \\ \delta_{12} \\ \delta_{13} \\ \delta_{14} \\ \delta_{15} \\ \delta_{16} \\ \delta_{17} \\ \delta_{18} \\ \delta_{19}\end{array}\right]$

$[E G T I]=\left[\gamma_{S A D M} \gamma_{U P E T I} \gamma_{A C D T I} \gamma_{A G P I T I} \gamma_{A C D T I, A G P T I}\right]=\left(\begin{array}{c}S A D M \\ U P E T I \\ A C D T I \\ A G P I T I \\ E G T I\end{array}\right)+\xi_{E G T I}$

$\Psi=\Psi_{E G T I}$

$\Phi=\left[\begin{array}{ccccc}\Phi_{S A D M-S A D M} & 0 & 0 & 0 \\ 0 & \Phi_{U P E T I-U P E T I} & 0 & 0 & 0 \\ 0 & 0 & \Phi_{A C D T I-A C D T I} & 0 & 0 \\ 0 & 0 & 0 & \Phi_{A G P I T I-A G P I T I} & 0 \\ 0 & 0 & 0 & 0 & \Phi_{A C D T I A G P I T I} \\ & -A C D T I A G P I T I\end{array}\right]$

Considera-se que a matriz $\delta$ é igual a matriz $\Theta_{\delta}$, pois os erros são independentes e restritos a relação entre as variáveis com elas mesmas.

A questão da independência dos erros e da existência apenas de erros restritos a relação entre as variáveis com elas mesmas também se aplica a matriz $\Phi$.

Além disso, considerando a ideia de variável marcada, considera-se $\lambda_{\mathrm{s}}=\lambda_{11}=\lambda_{14}=\lambda_{16}=\lambda_{18}=1$

Os itens do questionário (variáveis manifestas) são representados pelas marcações V8 a V19. 
As variáveis latentes são identificadas por siglas que apresentam os seguintes significados:

SADM = Suporte da Alta Administração

UPETI = Utilização do Planejamento Estratégico de TI

ACDTI = Atuação do Comitê de TI

AGPITI = Atuação da Gestão de Portfólio de Investimentos de TI

EGTI = Efetividade da Governança de TI

Desta forma, chega-se à conclusão que existem 31 parâmetros livres a serem estimados. 